\title{
The Reflective Epistemic Renegade
}

\author{
Bryan Frances
}

Philosophy and Phenomenological Research 81: 419-63

\begin{abstract}
:
Philosophers often find themselves in disagreement with contemporary philosophers they know full well to be their epistemic superiors on the topics relevant to the disagreement. This looks epistemically irresponsible. I offer a detailed investigation of this problem of the reflective epistemic renegade. I argue that although in some cases the renegade is not epistemically blameworthy, and the renegade situation is significantly less common than most would think, in a troublesome number of cases in which the situation arises the renegade is blameworthy in her disagreement with recognized epistemic superiors. I also offer some thoughts on what it would mean for philosophical practice for us to refrain from being renegades. Finally, I show how a new kind of radical skepticism emerges from modest theses regarding the renegade.
\end{abstract}

\section{The Epistemic Renegade Problem}

It's not terribly important on which claim David Lewis and I disagree. It might be some claim about modality, for instance. The problem is that even though he held that $-P$ while I hold that $P$, I know full well that he was my epistemic superior with regard to the issues surrounding $P$. Lewis could kick my philosophical ass when it comes to modality-or just about any issue in metaphysics for that matter. Not only that: he put much more thought into the question whether P than I ever will. He is my epistemic superior in just about every way when it comes to modality, I fully admit it, and yet I say that he's wrong and I'm right on that very topic. Things might be different if I actually did serious research in metaphysics, but I don't; my areas of expertise lie elsewhere. And of course, this has nothing in particular to do with Lewis or metaphysics. For instance, Saul Kripke, Crispin Wright, Timothy Williamson, David Chalmers, Bas van Fraasen, and a large and embarrassing number of other contemporary philosophers are my epistemic superiors in a huge range of areas as well, and yet I disagree with them even though I admit that they are my epistemic superiors on the very issues we disagree about.

Doesn't this mean that there is something deeply wrong with me? Are philosophers of average abilities just overwhelmingly and incurably arrogant? Shouldn't I withhold belief, or at least reduce my confidence level, once I discover that some of my recognized epistemic superiors disagree with that belief? More generally, what philosophical beliefs are professional philosophers epistemically blameless in holding? How should we conduct our philosophical lives? 
This situation arises not just with respect to philosophical belief. There are many occasions in which we believe $P$ even though we know full well that there are experts who believe the opposite while being our epistemic superiors in just about every relevant way with regard to $P$ and the topics surrounding $P$. Even though the problem generalizes, the philosophical case is particularly interesting given how reflective we are. It also hits close to home. ${ }^{1}$

By 'epistemic superior regarding $\mathrm{P}$ ' I mean to indicate something strong. Someone $\mathrm{S}$ is my epistemic superior regarding $P$ if and only if all of the following hold:

- $\quad$ S is generally more informed than I am on the topics involving $P$.

- $\quad$ Shas more raw intelligence than I do.

- $\quad$ Shas thought and investigated whether $P$ is true longer and in more depth than I have.

- $\quad$ Shas thought about and investigated the topics surrounding $\mathrm{P}$ longer and in more depth than I have.

- $\quad$ Sis just as or even more intellectually careful than I am.

- $\quad$ Sis no more relevantly biased than I am.

- $\quad$ Shas understood and fairly and thoroughly evaluated all the significant evidence and reasons I have regarding $P$ (and usually a great deal more evidence and reasons). ${ }^{2}$

Call someone my recognized epistemic superior with respect to $\mathrm{P}$ just in case I know that she is my epistemic superior with respect to $P$.

When I say that we know that so-and-so is our epistemic superior I don't mean we dwell on that fact whenever we reflect on our belief in P. Nor do I mean that we have consciously thought about and explicitly accepted each of the components of my above characterization of epistemic superiority with

\footnotetext{
${ }^{1}$ I'll have more to say on non-philosophical cases later in the essay.

${ }^{2}$ I don't mean to suggest that if A is B's epistemic superior with respect to $\mathrm{P}$, then A knows $\mathrm{P}$ and $\mathrm{B}$ doesn't. Nor do I mean that A's belief is true while B's is false. Nor do I mean that A's belief is more justified or epistemically better than B's. Nor do I mean that A is more reliable at arriving at the truth regarding the topic at hand. There's more on reliability in section 3 .

I can't define 'raw intelligence' (as it occurs in my characterization of epistemic superiority), but what I have in mind should be clear to teachers. It is easy to spot the undergraduates who are intellectually very quick, go right to the heart of the issues, don't get sidetracked with irrelevant or peripheral issues, display creativity in thinking through possible approaches, etc. Think of the glowing things you write in only moderately inflated or even honest letters of recommendation for your best students. These are usually the ones with high "raw intelligence".
} 
respect to P. Although I don't want any requirement that stringent, I do want something a bit stronger than 'We are disposed to correctly accept that so-and-so fits all the superiority conditions'. I want something realistic, something that actually applies to many of us philosophers who are confident enough to disagree with Lewis regarding some metaphysical claim, say, and yet wise and reflective enough to readily admit and be at least partially aware that he knew and understood quite a bit more than we do regarding the topics directly relevant to the claim in question. I want to pick out an epistemic situation we often actually find ourselves in when we contemplate how our views conflict with those had by people we know full well to be better philosophers than we are in these areas. But I'm not sure what that really amounts to; as a result I won't offer stipulations regarding 'epistemic superior' or 'know that so-and-so is my epistemic superior'.

Perhaps something along these lines conveys the relevant kind of awareness of disagreement in the face of epistemic superiority:

- I have consciously recognized that Lewis believes the opposite of what I believe.

- I have consciously recognized that he knows and understands quite a bit more about the topics germane to $P$ than I do.

- $\quad$ I am disposed to accept virtually all of the conditions in the above characterization of epistemic superiority with respect to $P$, applied to Lewis and myself.

- $\quad$ I am disposed to admit he's my epistemic superior while simultaneously realizing that we disagree regarding $P$.

I may not have ever actually said, all in one breath, 'Lewis is my epistemic superior regarding P but I'm right and he's wrong about $\mathrm{P}^{\prime}$, but I have admitted in one way or another all four bulleted conditions on several occasions. The fundamental problem-I seem epistemically blameworthy in believing $\mathrm{P}-$ is worse, perhaps, if I have asserted all the conditions in one breath. But even without the simultaneous assertion, I don't look too good.

Call the person who knows that her belief is denied by recognized epistemic superiors the reflective epistemic renegade. So the renegade isn't someone who merely believes P even though she has epistemic superiors who believe $-P$. It's stronger than that: the renegade knows that she believes $P$ and she knows that the epistemic superiors believe $-P$ and are her epistemic superiors regarding $P$; she is a reflective renegade. I will say that these philosophers are in the Epistemic Renegade situation. Finally, the Epistemic Renegade problem is the problem of figuring out whether the renegade is blameworthy in continuing with her belief in $P$.

It is a good question what terms can be substituted in for "know' in 'Someone is my "recognized" epistemic superior with respect to $\mathrm{P}$ just in case I know that she is my epistemic superior with respect to $P^{\prime}$ in order for the renegade problem to have bite. Is it enough that I just believe that so-and-so is my superior? Or do I have to justifiably believe it? Does my belief in so-and-so's superiority have to be true? I will sidestep these questions by focusing on real-life cases, in which (setting aside skepticism) I 
know full well that, for instance, Lewis was my epistemic superior when it came to the ontology of material objects.

I suspect that most philosophers are reflective epistemic renegades with respect to some of their philosophical opinions. If you're an epistemologist, then you will be a renegade with respect to an epistemological issue only if you really think that you have disagreeing superiors on that issue. You may be perfectly reasonable in thinking that you have no such superiors, even though Ernie Sosa, for instance, disagrees with you on the issue in question. Of course, you might be Ernie Sosa. But even if you aren't you may well think that even though Sosa's a better epistemologist than you are, you reasonably think that you're actually pretty expert on the issue at hand. You think of Sosa more as a peer on that issue, even though you admit he's your superior on other issues, including epistemological ones. When it comes to the philosophy of language or metaphysics, however, you'll admit that you have many more superiors, but you may have far fewer controversial beliefs in that area, thereby diminishing the frequency of the renegade situation.

My main question in this essay is this: under what conditions are reflective epistemic renegades epistemically blameworthy or blameless in continuing to believe P once they realize that recognized epistemic superiors believe $-P ?^{3}$ It's not the belief state itself or the initial coming to have that belief state that is in question; it's the retaining of it. On the face of it, I should-epistemically should-give up my belief once I recognize that people I admit are my epistemic superiors regarding $P$ believe $-P$. Or, if I'm currently on the fence regarding $P$ but strongly inclined to believe it, then given that I have reflected on the fact that some of my admitted epistemic superiors hold $-P$, I should refrain from coming to believe $P$.

An early objection: one might initially think it's obvious that I can reasonably disagree with someone I know to be an epistemic superior regarding the issue at hand. After all, it's not as if the superior is infallible. Philosophy is awfully difficult, and the phenomenon of widespread disagreement proves that even our best and brightest philosophers get things wrong quite frequently. But this observation cuts both ways: how can I reasonably think that it's the superior philosopher who got things wrong in the case at hand? I know perfectly well that I'm fallible too; and I also have admitted up front that the philosopher disagreeing with me is my superior with regard to the relevant issues; so isn't it more likely that I'm the one who has got things wrong this time around? This little line of argument proves nothing, but it does suggest that it's not so easy to reasonably disagree with recognized epistemic superiors.

Of course, we do not have complete control over our beliefs. But in many everyday circumstances similar to the Epistemic Renegade situation it is obvious that the epistemic charge 'You should not continue with your belief' is true. When it comes to scientific matters, for instance, we change our

\footnotetext{
${ }^{3}$ In other published (2005a, 2005b, 2008a, 2008b) and unpublished work I have examined closely related questions, especially emphasizing how "live" scientific-philosophical theories with radical consequences ruin one's chances at large classes of everyday knowledge.
} 
beliefs accordingly all the time when we discover that the experts disagree with us; and if we don't do so we are being epistemically naughty. For instance, on M onday you believe that Jupiter has about 20 moons. You've believed this for years, based on what you read about astronomy. Then on Tuesday you talk to your friend the physics professor who tells you that astronomers have now catalogued over 40 moons of Jupiter. Obviously, you should give up your old belief; you should know better than to stick with your old belief. I will simply assume that such epistemic 'should' judgments are often true (even though those judgments might come out false on alternative interpretations, due to polysemy). I will make a few conjectures about how to understand the relevant epistemic judgment later in the essay.

Recently there has been some illuminating work on the epistemic problems of peer disagreement. ${ }^{4}$ Two people disagree regarding $P$ (i.e., one believes it while the other believes its negation) even though they are equal in intelligence, biases, and intellectual care-both generally and with regard to the topics surrounding $P$. They have also been exposed to the same evidence and have worked on it comparably long, carefully, etc. They are epistemic peers with respect to P. Not only that: they know, or at least firmly believe, that they are peers. Such a situation generates several good questions, but I think it virtually never shows up in either philosophy or politics, for instance. In order for philosophers Fred and George to be peers in this sense they would have to have the same evidence regarding $P$, and presumably that would mean that they have read just about the very same literature on $P$ (not every article, but surely the main ones). But that virtually never happens in philosophy; I don't think we even come close to it in most circumstances, as there is quite a bit of diversity in professional philosophy even regarding our reading of the "central" works. Often the Peter van Inwagen (1996) example of his disagreement with David Lewis regarding the compatibility of free will and determinism is cited as an actual case of recognized disagreement with equal evidence, but I have a hard time believing that those two philosophers had considered literally the same evidence-even if we mean by 'same' approximate sameness. And of course if by chance they had seen the very same evidence, they probably wouldn't be a position to reasonably think they had. I can't name even one epistemic peer of mine with regard to any interesting philosophical issue, even on a relaxed interpretation of 'epistemic peer'. I know of plenty of philosophers who are roughly as intelligent and intellectually careful as me, but that's not enough for peerage. It's virtually never true that they have read just about the same literature on the topic in question as I have.

And even if they have, and by some miracle I know that fact, I haven't much of any idea what thoughts went through their minds while digesting that literature-and that's a factor crucial in determining peerness in the intuitive sense. How one digests a philosophical work is often highly dependent on one's familiarity with what initially may strike someone else-including an approximate epistemic peer-as irrelevant philosophical material. Furthermore, how one digests a philosophical work is highly dependent on what connections happen to pop into one's mind while thinking about the work's

\footnotetext{
${ }^{4}$ For instance, see Feldman 2006 and 2007, Kelly 2006 and 2008, Elga 2007, White 2005, Lackey forthcoming A and forthcoming B, and Christensen 2007. For an introduction to some of the main questions on this topic, see my 2009 or Christensen 2009.
} 
content-a factor that is highly variable. Finally, I may approach a philosophical issue in a way completely different from that taken by someone else, even if that person is of the same abilities and has read the same literature. For instance, I might approach issues with 'What is the logic of the position here? And has the position been filled out thoroughly?', whereas someone else might focus almost entirely on 'Is the view as defended true? Are the supporting arguments conclusive?' So it seems unlikely, given differences in personal history, memory, approaches, and interests, that any two people digest the same bit of literature in the same way-even with a relaxed notion of 'same way'. Furthermore, unlike my rough peer I may be the type of person who is epistemically very cautious, valuing the avoidance of false beliefs and blind alleys much more than the acquisition of true beliefs and promising lines of argument (for instance; there are other ways we can differ in epistemic values); if so, then we may be epistemically quite different. It's easy enough to define a relatively clear notion of philosophical peerage, but in order to engage with practical concerns-which are my focus in this essay - we need peerage to actually happen and be known to happen. However, the Epistemic Renegade situation, which focuses not on peerage but superiority, clearly does have plenty of real-life application. $^{5}$

In this essay I will be offering a mixed solution to the Epistemic Renegade problem, arguing for two main theses, although the former will receive the bulk of support here (the latter is more thoroughly treated in my unpublished work).

Favorable Thesis: there might be four (or more; I don't know about this) real-life (and not heavily idealized) species of the Epistemic Renegade situation in which the reflective epistemic renegade is not blameworthy in virtue of being a reflective epistemic renegade (of course her holding of her belief might be blameworthy for some other reason).

Unfavorable Thesis: if (a) one is a reflective epistemic renegade with respect to one's belief in $P$, and (b) one isn't in any of the four exception cases, then one's retaining $P$ is blameworthy.

Note that the Favorable Thesis has the consequence that I'm blameless in disagreeing with an epistemic peer as well as a superior (if I'm epistemically entitled to disagree with the superior, then surely I'm okay in disagreeing with the peer); so my theses have bearing on the peer problem. If my theses are true, then the straightforward responses to the peer problem, 'Stick with your belief', 'Stick with your belief if it was the justified one in the first place, before the discovery of disagreement', and 'Give up your belief

\footnotetext{
${ }^{5}$ One might suspect that many reasons for belief are incommunicable, in practice if not in theory. If so, then it might seem difficult to know that so-and-so is my epistemic superior on some issue, as that requires me to know that so-and-so has virtually all my evidence and reasons regarding P. But I think that once we proceed to real cases of disagreement in philosophy the worry very often (though not always) is idle. For instance, there is no reason I know of to think that I have some good reason for my belief against instantaneous temporal parts that Ted Sider lacks.
} 
or significantly lower your confidence in it', are incorrect. In addition to arguing for those two theses, I will suggest that the problem arises significantly less frequently than it appears (for reasons I'll describe in section 4), even when we are aware of our lower level of expertise compared to that of our superiors. Finally, and provocatively, the Unfavorable Thesis leads to a kind of radical skepticism significantly different from and more plausible than traditional forms of skepticism. ${ }^{6}$

One could be forgiven for initially thinking that it's pretty clear that one is blameworthy in at least the most obvious instances of the Epistemic Renegade situation, that there are no good reasons to think otherwise, and that therefore this essay is investigating a thesis of no importance. (Notice that this objection is precisely the reverse of the "early objection" noted a few paragraphs back.) However, for almost any interesting philosophical claim $P$ that I'm aware that I have, I know of two people who are my epistemic superiors with respect to $P$ and they disagree with one another. ${ }^{7}$ How can I reasonably either believe P or disbelieve P (i.e. believe $-\mathrm{P}$ ) in such a situation? No matter what I do, I'll have to admit that I'm disagreeing with an epistemic superior. Thus, it seems that the reasonable thing to do, for those of us who are reflective enough to know of our relative philosophical ability and understanding, is to withhold judgment on most every worthwhile philosophical claim. Most philosophers will find this distasteful. Still, it might not sound that hard to alter one's epistemic practices so as to not fall into the Epistemic Renegade situation anymore. But once one starts actually listing one's philosophical beliefs and noting which ones are known perfectly well to be denied by recognized epistemic superiors, one sees how difficult it is to follow the advice, and not merely nod one's head at it. This is especially true for those who like me are generalists, working in several areas. And no cheating: it's no good, I think, to insist that despite all the verbal and written evidence to the contrary, one has no beliefs for which the Epistemic Renegade problem comes up. That's almost always disingenuous; I don't think I've ever met more than a few philosophy professors who weren't reflective epistemic renegades. ${ }^{8}$ Look through your own writings and list the claims you've defended or, better,

\footnotetext{
${ }^{6}$ One could argue for blameworthiness not via contemporary disagreement but via the diversity of superexpert opinion throughout history (e.g., Hume, Kant, and Aristotle) on major philosophical issues (e.g., compatibilism, the existence of universals). I think this argument merits investigating (although I'm inclined to think it will fail), but in this essay I will confine my attention to the problem of recognized contemporary epistemic superior disagreement, particularly as it shows up in philosophy. Only by sticking with contemporaries can we fruitfully compare bodies of evidence.

${ }^{7}$ Actually, this is misleading, as I personally have almost no even remotely controversial philosophical beliefs (not even that there are chairs or rocks, although I do indeed believe that $2+2$ isn't 57). This puts me well out of the mainstream; for the sake of the arguments in this essay its protagonist is somewhat fictional.

${ }^{8}$ It isn't clear to me how many students really fit the conditions for being epistemic renegades, since many of them don't believe that David Lewis, for instance, is their epistemic superior when it comes to
} 
explicitly assumed as "obvious" or "clear" or "evident" or "manifest" or "certain" or "definite" or "unmistakable" or "inevitable" or "indisputable" or "surely right", and then note how many of those put you in the Epistemic Renegade situation. Better yet: grab a few journals and consider how many of the defended theses you believe to be false, even though others who you admit to be your superiors think they are true. Maybe best: in relatively private encounters see what your philosophical colleagues and acquaintances say about various philosophical theories (e.g., "All that crap that's been published on possible worlds"). You need to deal with genuine modal realism, propositional attitude eliminativism, moral error theory, color error theory, dialetheism, epistemicism, virtually every mature and defended metaphysical view about ordinary physical objects, and dozens of other counterintuitive theories supported by some of our best and brightest.

\section{Clarifying the Problem}

Our general problem is a large and personal one: what philosophical beliefs should I have? I like to think of the more particular problem - should I continue with my renegade ways? - in the following convenient and illuminating way. I say $\mathrm{P}$, where $\mathrm{P}$ is some controversial bit of philosophy. Then my fiveyear-old daughter says $-P$. I'm not too worried that I might be mistaken. The fact that she disagrees with me gives me no good reason to doubt my belief. Then an undergraduate philosophy major of average abilities says $-P$. I'm still not worried that my belief in P is mistaken. Then I discover that many of my epistemic peers (where we construe 'peer' so that it actually applies in such a way that I can identify philosophical peers as peers) regarding $P$ and the topics surrounding $P$ say that $-P$. Now I'm a bit worried but hardly upset. Then I die, knowingly come face to face with God, and God says that the truth is definitely $-P$. At this point only an idiot would retain his belief in P. Surely at this point I have to admit I was wrong - or at least withhold judgment! It seems that there is a continuum of degree of blameworthiness. In the situation with the five-year-old, I'm not blameworthy in persisting with my belief (degree zero); in the situation with God I'm a moron if I retain my belief (just about the highest degree of blameworthiness); these claims are hard to contest. Our issue is whether people in the Epistemic Renegade situation are in a bad enough position among this continuum to be blameworthy.

In the rest of this section I'll offer two comments meant to further clarify the Epistemic Renegade problem. Then in the remaining sections, I'll try to determine when reflective epistemic renegades are or are not blameworthy.

First point. We are not questioning the choice of research direction of the renegade philosopher. There is nothing at all wrong, I submit, with choosing to pursue a line of reasoning or theory based on an assumption that one knows full well is denied by many, even the vast majority, of one's recognized epistemic superiors. None of the arguments of this essay suggest otherwise; there is nothing here to

metaphysics. This is not to say that they believe that he isn't their superior; it's to say that they haven't thought it through enough to become renegades. Keep in mind that being a renegade requires quite of bit of sober reflection (although a realistic amount); it isn't unreflective epistemic recklessness. 
stifle research. For one thing, one simply must choose some research project with underlying assumptions; otherwise it would be very difficult to do any research at all. And in most cases if one is going to do any research that has a chance of being interesting, one is going to be making some assumptions that are denied by recognized epistemic superiors. This is especially true for me, since I am an average philosopher who will probably not have the originality to embark on an interesting line of research resting on uncontroversial assumptions. So I'm pretty much forced to be a "research renegade". In any case, there are good reasons for strongly encouraging people to be research renegades. One is not similarly forced to believe the assumptions underlying one's research or the conclusions derived from them. What looks unwise is believing that the superiors are wrong; the focus is on belief, not action. Clearly, one can vigorously pursue a line of thought based on a controversial assumption without believing the conclusions derived along the way. Being a reflective research renegade is one thing; being a reflective epistemic renegade ('reflective doxastic renegade' is more descriptive but uglier) is something else. So in one sense the answer to 'How should we conduct our philosophical lives?' is 'W ith complete freedom!', as there is little reason (from disagreement alone) to restrict action. ${ }^{9}$ I'll return to this point in section 5.

Second point. What exactly is the alleged epistemic blameworthiness in question? Maybe in these cases it is just good old irrationality. But the charge of irrationality is too general and ambiguous to be informative. Furthermore, to my ears anyway the accusation of irrationality typically conveys a major insult-at least for a professional philosopher with regard to her professional philosophizing. I want to tentatively charge those of us in the Epistemic Renegade situation with something like hit-and-run, with no injuries, on a side street, in snowy conditions, at 15 or $20 \mathrm{mph}$, and with just some dents and scrapes on the parked car; not plowing into a crowd of pedestrians while drunk.

The kind of blameworthiness in question is best given with examples. As a graduate student in physics I work on a problem in advanced classical mechanics, say, and then find that my answer isn't the same as my professor's, which in turn matches the answer key in the back of the physics textbook. Wouldn't I be pretty foolish to continue to believe that my answer is the right one-given that I admit the relative superiority of my professor's ability (as well as that of the textbook authors)? That's the kind of epistemic blameworthiness I have in mind, illustrated with an extreme instance.

\footnotetext{
${ }^{9}$ Interestingly, this doesn't apply to many non-philosophical cases. Suppose I'm a physician who disagrees with $98 \%$ of a group of physicians I know to be my superiors regarding the case at hand. I believe that treatment $\mathrm{A}$ is significantly better than treatment $\mathrm{B}$; they all believe that $\mathrm{B}$ is significantly better than A. A great deal rides on the decision of how to act; a life is in the balance. If it turns out that I would be blameworthy to retain my belief, it should also turn out that I'm blameworthy to act on my belief. This doesn't, however, mean that I need switch to their judgment; I may reasonably act on their belief (going ahead with treatment B) while withholding judgment on whether B is better than A.
} 
We tend to have two reactions to this example. Reaction one: we think that since we philosophy professors are all pros now, the typical graduate student-professor chasm of competence or reliability no longer holds. A graduate student disagreeing with a professor is one thing; one philosophy professor disagreeing with another is something else entirely. But if you're in the Epistemic Renegade situation, then you know that that's erroneous for many of the topics on which you have opinions but are not a leading expert: there's a chasm of understanding/competence separating me from Timothy Williamson on vagueness issues, David Lewis on metaphysics issues, David Chalmers on phenomenal consciousness issues, etc. I don't want to exaggerate: it's certainly less of a chasm than in the case of the physics graduate student and physics professor! (We'll consider an interesting development of this idea in section 3.) And whereas in the physics case virtually all the physics professors will agree on the answer to the physics problem, no such near universal agreement will hold in the philosophical cases. But there's a chasm of understanding and competence all the same. There probably is no chasm for the areas in which one publishes with some frequency and success; but philosophers rarely restrict their philosophical beliefs to such areas. Keep in mind that the renegade problem shows up with most frequency regarding areas outside one's areas of maximum expertise; that's where the problem has its bite. $^{10}$

As just noted, we know that in the case of philosophical research there almost never is an interesting situation in which the answer is clear to all the real experts, as there is in the physics case. (Indeed, if the answer did become clear to all the experts, then eventually the answer would no longer be interesting, even if it started out interesting.) Thus, our second reaction to the physics case is something like, 'So because of the greater uncertainty or difficulty here in philosophy compared to graduate physics, I'm okay in disagreeing with the philosophical superiors.' But it seems to me that that only suggests that you should have little confidence in your philosophical inclinations. You should say, 'Well, heck! Given that in philosophical research we're squarely in the realm of the exceedingly difficult and uncertain, compared to graduate physics, I should have less confidence in the opinion of the experts and that of myself, as I know I'm not nearly as good as those experts on these topics. ${ }^{11}$

\footnotetext{
${ }^{10}$ As a consequence, I won't investigate the case in which you believe P but you have looked at all the reasons your superiors have offered in print to accept $\neg \mathrm{P}$, you have given all their public arguments a fair, thorough, and expert examination, you are a genuine international expert in the area in question, and you have subsequently and expertly concluded that the public arguments aren't very good; so you have retained your belief in P. This is an interesting case, but it is different from the ones I examine in this essay because it is so exhaustive.

${ }^{11}$ A relevant difference between the physics and philosophy cases: whereas in philosophy it's perfectly epistemically acceptable to pursue lines of research in conflict with the mature opinions of one's epistemic superiors (because we can have little confidence that the superiors have reached the truth), the same is rarely true of the graduate physics student, since we have lots of confidence that her superiors
} 
However, at this point I'm only asking you to understand the charge of epistemic blameworthiness being made of the reflective epistemic renegades, not believe that it is correct. In subsequent sections, I will evaluate the charge.

Here is another example, one that helps indicate what kind of blameworthiness I don't have in mind as well as hinting at what kind might be applicable. If Tom is a philosophy professor currently specializing in the philosophy of mind, and in 2010 he confuses eliminativism (no beliefs) with physicalist reductionism (beliefs are physical), then he is epistemically blameworthy in a professional sense. Pros can do boneheaded things, including epistemic things. But even though Tom is blameworthy, his kind of mistake seems importantly different from that of the reflective epistemic renegade. Tom has made an error in his work, in his philosophizing; by being a reflective epistemic renegade, I seem to have made an error in my philosophical conduct, with my attitude towards my philosophizing. This may make it sound as though I've done something morally wrong, but that isn't right. Tom's mistake counts against his philosophical competence; mine seems to diminish my chances of philosophizing wisely.

If my mistake lies in my attitude toward my philosophizing, as was just suggested, then perhaps I'm blameworthy because of my beliefs about my philosophical beliefs. In particular, perhaps the (alleged) blameworthiness of my position in the Epistemic Renegade situation comes from my unjustified belief that my belief in P is more justified than Lewis's belief in $-P$. It might be thought that in order for me to continue to believe P in the Epistemic Renegade situation I must at least be disposed to think that Lewis has made some error that I've avoided, or that I've found some piece of evidence that he has missed or not fully appreciated, and as a result my belief in $P$ is more justified than his belief in $\sim P$. Otherwise, why would I persist in my belief when I'm fully aware that my superior Lewis disagrees with me? And it's that belief disposition that is the source of my blameworthiness.

I don't accept that view-call it the Second-Order Belief view. For one thing, it fails to target the right belief. To see this, consider what I will call the "extreme renegade". He has examined a good deal of evidence concerning philosophical proposition $\mathrm{P}$. He concludes that $\mathrm{P}$ is true. At this point he is not, however, aware of the opinions regarding $P$ of many of his superiors (aware of some, perhaps, but not many). It is a bit difficult to imagine such a situation now, with so much communication among philosophers, but of course the present communicatively rich situation isn't necessary to philosophy. He then comes across a recent poll of virtually all contemporary philosophers regarding $P$ (as well as other propositions). For the most part he knows who his superiors are. There are 100 of them on the list, and he is able to spot every one of them (or, more realistically, nearly every one). 98 of his recognized superiors on the list think $P$ is false. That's 98\%! Furthermore, of the 400 philosophers polled who are known by him to be neither superiors nor inferiors (on the topic in question), 392 think P is false (98\% again). Now you tell me: should the extreme renegade shift his position on P?

have reached the truth (keep in mind that this is run of the mill graduate physics, not cutting edge material). 
The answer seems perfectly clear: only a foolish philosopher would fail to lower his credence in P; in fact, he would be foolish not to give up his belief in P entirely. ${ }^{12,13}$ One might protest: what if the 98 superiors all made errors in coming to their view, and he was epistemically perfect in his route to his opposite view? He believes P for the "right reasons" while they believe -P for the "wrong reasons". In such a case surely he should stick with his view, and not give it up! But no: it's still the case that he is blameworthy in sticking with his belief. His route to his belief isn't blameworthy, but his retaining of his belief is blameworthy because his evidence regarding $P$ has just suffered a huge transformation upon reading the poll results. He has now obtained extremely good sociological evidence $E_{1}$ (via the poll) that there are pieces of evidence $E_{2}$ not sufficiently appreciated by him and against $P$ that are so powerful that they convinced 98 out of 100 of his superiors that $P$ is false. ${ }^{14}$ The rule 'If you have come to believe $P$ in an epistemically perfect way, and $P$ is true, then you should keep your belief come what may' is an excellent rule of thumb, but we can see that there are counterexamples. Of course, the 98 superiors are blameworthy as well (not because they knowingly disagree with him but because of their route to their

\footnotetext{
${ }^{12}$ One can think of ridiculous counterexamples. I start out with just three superiors regarding P, two agreeing with me and one disagreeing with me. Then the disagreeing one perfectly clones himself 97 times. So, I end up with 98 disagreeing superiors and just two agreeing superiors. Or, I discover that all 98 superiors (no clones this time) believe $\neg \mathrm{P}$ only because they hate the two remaining superiors (in effect, the 98 are epistemic near-clones with respect to $\mathrm{P}$ ).

${ }^{13}$ Why not just accept what they say, given that they are nearly unanimous on P? I might do so. On the other hand, I might not because of a general skepticism regarding our ability to reach the truth about philosophical claims. When I say that so-and-so is my philosophical superior concerning P I am saying that they are better than me in several important epistemic respects, but I need not hold that they have a good chance of being right. If I do have this general skepticism I probably will only rarely have any philosophical beliefs myself, and so the Epistemic Renegade problem will arise infrequently.

${ }^{14}$ Actually, $E_{2}$ might not count as evidence under a narrow construal of 'evidence' (although $E_{1}$ is evidence under any construal). Throughout this essay I use 'evidence' in a broad if slightly non-standard way so as to include epistemic factors other than beliefs (e.g., experiences, reliability facts, etc.) that in some way help make beliefs not blameworthy. However, in most cases we are investigating $\mathrm{E}_{2}$ will be ordinary evidence, as we are considering philosophical beliefs most of which are based on arguments. If you insist, you can restrict the argument to cases in which $E_{2}$ is ordinary evidence; the argument won't diminish in interest. In my Forthcoming I attempt to give a more theoretical answer the question 'Under what conditions am I epistemically blameless/blameworthy in retaining my belief after I have discovered recognized peers or superiors who disagree with me?'
} 
belief), but the point is that he is blameworthy too (not because of his route but because of his reaction to his new evidence $E_{1}$ ).

My main point: the extreme renegade isn't merely blameworthy in thinking that his belief in $P$ is justified. Or that his belief in $\mathrm{P}$ is just as (or more) justified as those of his superiors. Or that his belief in $\mathrm{P}$ isn't blameworthy. Instead, the belief in P itself is blameworthy. So the Second-Order Belief view is mistaken.

Despite that consequence, I think there is something importantly right about the Second-Order Belief view, something having to do with the nature of wisdom. As I stated above, if I'm blameworthy in virtue of being a renegade, then the problem seems to lie in my attitude toward my philosophizing. The renegade is being foolish or unwise, but not stupid or blundering. My guess is that the person who is a frequently blameworthy renegade is simply bad at appreciating what might be called elusive higherorder evidence, and it is a (minor) mark of wisdom that one can appropriately appreciate such evidence. By 'elusive higher-order evidence regarding $\mathrm{P}^{\prime} \mathrm{I}$ mean this: purely testimonial evidence $\mathrm{E}_{1}$ that there is such-and-such significant evidence $E_{2}$ regarding $P$, where $E_{2}$ is utterly unknown to the subject despite her efforts (if any) to grasp it (so $E_{1}$ is the higher-order evidence and $E_{2}$ is the elusive evidence). The excellent "first-order philosopher" can expertly evaluate loads of evidence concerning P but has real psychological difficulty dealing with the fact that others have plenty of evidence regarding $P$ that she knows nothing about despite her efforts to grasp that evidence. Often, these are philosophers who are excellent at "doing philosophy" but who simply can't stand the thought that there might be strong evidence against their view that they don't know about or have yet to sufficiently appreciate. But "out of sight, out of mind" is a not a wise strategy in philosophy.

One might wonder why I stick with 'epistemically blameworthy' instead of 'epistemically unjustified': the problem with the epistemic renegade is that she is unjustified in retaining her belief, so why not set blameworthiness aside? I'm not against this substitution. My main reason for focusing on blame is that I'm interested in the question 'How should we conduct our philosophical lives?' I'm interested in what we should actually do, how we should react, when we find ourselves in the epistemic renegade situation. When the renegade is blameworthy it will often be due to the fact that she is unjustified, overall, in believing P (both propositionally and doxastically). But in this essay I'm not so concerned with analyzing the reason why one may or may not be blameworthy (in unpublished work I consider the matter further).

\section{When Renegades Are Blameless}

The conclusion suggested thus far is a partial answer to the age-old and quite personal question of what important beliefs we should have: when in the Epistemic Renegade situation, withhold belief; if you 
don't, you will be blameworthy. ${ }^{15}$ If a reflective epistemic renegade is not epistemically blameworthy in sticking to her guns, then there is some interesting explanation of that fact. Prima facie, she looks blameworthy.

However, that's just a comment on appearances. I don't think there is any good reason to think the renegade is always blamew orthy in sticking with her belief in $\mathrm{P}$. Neither do I think that the renegade is always blameworthy in not lowering her credence in P. In this section as well as section $5 \mathrm{I}$ 'Il look at fourteen arguments for the conclusion that in at least some interesting cases renegades aren't blameworthy. I think ten of them aren't good; they are examined in section 5. In this section I will argue that there are at least four species of the Epistemic Renegade situation genus in which there is a good chance that the renegade is not epistemically blameworthy in virtue of being a reflective epistemic renegade and in some cases need not lower her confidence in $\mathrm{P}$, even a little bit. ${ }^{16}$ In fact, these four "exception cases" provide the topic with much of its interest, at least in my judgment. Keep in mind that in this essay we are focused on real-life scenarios; so highly idealized exception cases aren't to the point.

First species: undefended assumptions. You believe $P$ and successfully and knowingly trace the source of your disagreement with your disagreeing epistemic superiors such as David Lewis to a single and highly fundamental assumption, $Q$. Lewis flags $Q$, admits that his entire case against $P$ relies on $Q$, and sheepishly admits that although $Q$ strikes him as true, and thus good enough to rule out $P$, he has absolutely nothing to say in its defense. Q strikes you as false, and you may or may not have supporting arguments. In this type of situation, perhaps you're epistemically blameless in sticking with your (full confidence in your) belief in $\mathrm{P}$ - provided this works with all the other recognized epistemic superiors who deny $P$. For you know that the only articulated reason against $P$ is $Q$, and Lewis doesn't have any articulated reason for $\mathrm{Q}$. I'm not sure about that, but let's be generous and not challenge your

${ }^{15}$ Of course, there are legions of philosophers who are clearly epistemically inferior to Lewis, Williamson, Chalmers, etc. and yet who not only disagree with those superiors on the relevant topics outside their own expertise but will deny that those philosophers are their superiors with regard to the topics in question. So they aren't renegades in the sense characterized in this essay. I suspect they usually are epistemically blameworthy, although I won't argue the point here.

${ }^{16}$ Just because one is not blameworthy in virtue of being an epistemic renegade with respect to one's belief that $\mathrm{P}$ doesn't mean that one is epistemically blameless with respect to that belief, as one could be blameworthy in believing P in virtue of some other fact. In addition, if one does reduce one's confidence level (perhaps all the way to withholding belief entirely) as a result of being a renegade, this does not mean that one's so doing is blameless, as one may have made blameworthy errors in one's assessment of alleged superior opinion. I've omitted these qualifications in the rest of the essay. 
epistemic status in that situation. ${ }^{17}$ Even so, I don't think this type of situation happens often (although it does happen). For one thing, you need to have actually traced the source of the disagreement to that one fundamental point, you need to have noted the fact that the superior's endorsement of that point has no backing reason, etc. That's a lot of work, and when it comes to philosophical positions outside our main areas of research we have rarely done that work.

However, there is a similar situation that may appear to offer some hope for the renegade. I trace Lewis's argument for $P$ to his reliance on $Q$, which I reject. I now ask myself: is he my superior on Q? If the answer is 'Yes', then nothing has really changed, as I'm still in the renegade situation. But suppose I then find out that his argument for $Q$ relies essentially on the truth of $\mathrm{R}$, which I reject. And I know that he is not my superior on $\mathrm{R}$ ! If we are rough peers on $\mathrm{R}$, then I'm probably not helped very much in the matter of my blame status. But if I know that I' $m$ his superior on $R$, then everything changes: I no longer recognize him to be my superior on $\mathrm{P}$ or $\mathrm{Q}$. I know that I'm his superior on $\mathrm{R}$, which means I probably have significant evidence $E_{R}$ regarding $R$ that he lacks, but due to the relationship among $P, Q$, and $R$, my evidence $E_{R}$ that he lacks is now significant evidence against $Q$ and $\sim P$ that he lacks, which means he is no longer my superior on either $\mathrm{Q}$ or $\mathrm{P}$ (or $-\mathrm{P}$ ). This does not mean that I' $\mathrm{m}$ his superior on either $\mathrm{P}$ or $\mathrm{Q}$ (since he may still have significant evidence regarding $P$ or $Q$ that I lack), but it does mean that he is not my superior on P or Q. Now my disagreement with Lewis doesn't look so threatening. However, even if all this is right, I wonder how often this kind of situation actually turns up. I won't try to adjudicate that matter here.

Second species: forgiving percentages. I am blameless when I know that my superiors agree with me by a ratio of 10 to 1 , say. I believe that Peter van Inwagen, Trenton M erricks, and Cian Dorr are wrong to believe that there are no chairs, and luckily for me there are at least 30 other metaphysicians who agree with me (pretend). Although the epistemic credentials of the three (near) compositional nihilists gives me potent evidence that there is potent evidence for compositional nihilism, the credentials of the 30 other metaphysicians gives me potent evidence that the case for compositional nihilism isn't that strong and those three philosophers have made errors of some kind, even though they are among my recognized epistemic superiors when it comes to the metaphysics of composition. Of course, if those three philosophers were head and shoulders the superiors of the 30 philosophers, and I knew that, then I couldn't comfort myself with the 10 to 1 ratio, but let's set that possibility aside. So in some cases one is blameless in not at all diminishing one's confidence in P even though one is perfectly aware of multiple

${ }^{17}$ This kind of case brings up the topic of epistemic "starting points". If you don't have a reason to accept $\neg \mathrm{Q}$, then it might look somewhat arbitrary that you continue to reject $\mathrm{Q}$ while in full knowledge that Lewis accepts Q as his starting point. But it seems to me that even if the charge of arbitrariness is correct, and one even admits it, that doesn’t mean that one lacks epistemic upstandingness in continuing with $\neg Q$; an arbitrary decision in starting points need not be epistemically unsightly. Just because you lack a reason to prefer your starting point over Lewis's does not mean that your starting point is blameworthy, or so it seems to me. 
epistemically upstanding superiors who expertly believe $-P !^{18}$ In this case it might be hard to see how the three metaphysicians can be reasonable in their belief in compositional nihilism. But they might reasonably think they are the superiors of the other 30 metaphysicians.

The case has some significant real-life application. As graduate students in philosophy we often first hear about and study theses without knowing what the profession as a whole thinks of them. Later we learn what other philosophers think; we also come to have views about our abilities compared to those philosophers. For instance, suppose that working with standard philosophy of mind textbooks and articles as a graduate student I come to think that analytic behaviorism is false. I have looked at a great deal of the relevant considerations but haven't paid attention to what the profession thinks about behaviorism (this scenario was more realistic a few decades ago when there wasn't so much communication among philosophers). My belief is reasonable based on the epistemically significant considerations available to me. Suppose I then discover that virtually all professional philosophers of mind over the last few decades have thought that analytic behaviorism is false; I consider these philosophers my peers or superiors with respect to the philosophy of mind generally and behaviorism specifically. Naturally, I am reasonable in retaining my belief. Still later I find out that there are a couple renegade philosophers of mind Smith and Jones who today believe analytic behaviorism is true even though they're both aware of the reasons everyone else has rejected behaviorism. I will of course find this a bit puzzling, since I know that Smith and Jones are high-quality philosophers (including being my superiors on the metaphysics of mental content and belief) who have looked at all the considerations I and the other peers and superiors have seen, but I'm hardly unreasonable, to any degree, in continuing to stick with my old belief that behaviorism is false. There is nothing amiss in my inferring that it's highly probable that they made some odd mistake somewhere, despite their credentials and their superiority over me. After all, their opinion is outweighed by that of hundreds of other professional philosophers who still think that analytic behaviorism is false and do so even after looking at the arguments of Smith and Jones.

Third species: fragile blamelessness. As with the last species, this one may have fairly widespread application. Some renegades are happy to admit that Lewis, for instance, has seen all the crucial evidence regarding $P$ that they possess. Their only beef with Lewis might be that he either made a mistake with that evidence or hit on some additional and misleading evidence that led him astrayerrors that they have been lucky enough to avoid. These things happen all the time, even to the best of us. Why can't the renegade just point out that fact when explaining why she is sticking to her guns? (I'II explain the meaning of 'fragile blamelessness' below.)

That may seem like an explanation that gets the renegade off the hook. But if we apply the explanation generally, to many of my disagreements with Lewis for which I'm a reflective renegade, it seems to fall apart. I end up saying that Lewis has made mistakes with evidence or has acquired misleading evidence-each of which I've avoided-on philosophical claims A, B, C, D, E, etc. What amazing luck! In

\footnotetext{
${ }^{18}$ I discuss cases similar to the one described in the text in my Forthcoming.
} 
each case I, the average philosopher, have dodged philosophical mistakes that keep plaguing my epistemic superiors! In fact, I should conclude that he isn't my superior on these many issues in metaphysics. And since there are many such issues, Lewis isn't my superior at all in metaphysics. But that's silly. For most cases, I haven't the slightest reason to think that that Epistemic Renegade case is special in that I have avoided some mistake the epistemic superior has made. Similar considerations show that I cannot defend myself by supposing or concluding that the epistemic superior has had an uncharacteristic bout of argumentative sloppiness or excessive bias. I can't reassure myself with this: such-and-such considerations $C$ show that $P$ is true; David thinks $P$ is false; David knows about $C$ (and he has sufficiently appreciated its import); so I guess David just really screwed up in thinking about the C-P connection; after all, he's not infallible. Neither can I reasonably believe that the superior hasn't sufficiently appreciated the quality of such-and-such evidence. In most cases, I have no special reason to think that any of these things have occurred. ${ }^{19}$

The preface paradox threatens here to suggest that even when applied generally the 'This is a special case or he is not my superior' excuse is enough to escape blame. ${ }^{20}$ I encounter disagreements $D_{1}-D_{4}$ with Chalmers on phenomenal consciousness issues; disagreements $D_{5}-D_{8}$ with Lewis on modality; disagreements $D_{9}-D_{12}$ with Sider on material composition; $D_{13}-D_{16}$ with Williamson on vagueness; $D_{17}-D_{20}$ with van Fraassen on philosophy of science issues. When $D_{1}$ comes up suppose I think to myself 'Well, this case is special in that Chalmers has just screwed up, or maybe he's not my superior after all when it comes to this specific issue'. Then suppose I do the same with $D_{2}, D_{3}$, etc. But at the end of the day I admit that the 'This is a special case or he is not my superior' explanation is not true for all of $D_{1}-D_{20}$, as that's so unlikely (I'm virtually certain that several of these people are my superiors on at least several of those particular propositions). This combination of attitudes is inconsistent, but that might not mean that I'm guilty of any epistemic crime. If you think that the solution to the preface paradox is that one can have justified inconsistent beliefs that are known by one to be inconsistent, then perhaps you'll apply the same lesson here. This isn't crazy: the preface paradox does have a similar structure, and it

${ }^{19}$ On the same front, it is hopeless for me to argue thus: well, I thought that Chalmers, say, was my epistemic superior when it comes to the philosophy of phenomenal consciousness, but given that we disagree on these eight (say) crucial points, I guess he really isn't my superior in that subfield—or at least he's less reliably right than I initially thought. For I don't think that he's my superior based on his conclusions. I base it on many factors: how he conceives of certain issues, how illuminating his arguments are, the frequency and places he publishes, the amount and range of expert discussion he has engaged in, etc. When I discover the extent of our disagreement, this won't, or shouldn't, shake my judgment of epistemic superiority unless the extent is enormous in the sense that many central changes would have to be made to my belief system in order to make it match his (so we don't differ on just a couple fundamental assumptions from which the rest of our disagreement flows).

${ }^{20}$ Thanks to Ernie Sosa for drawing my attention to the relevance of the preface paradox. 
isn't implausible to hold that the paradox shows that one can have justified inconsistent beliefs that are known by one to be inconsistent. In the preface paradox I come to have philosophical beliefs $B_{1}-B_{20}$ but since I know of my own epistemic weaknesses, I also strongly believe that I am mistaken in at least some of $\mathrm{B}_{1}-\mathrm{B}_{20}$. In the "disagreement paradox" I initially come to believe $\mathrm{B}_{1}-\mathrm{B}_{20}$, I then come to believe, from the fact of disagreement, $S_{1}-S_{20}$, where $S_{x}$ is the proposition 'This case $X$ is special in that the epistemic superior with respect to $B_{x}$ just screwed up, or this alleged superior with respect to $B_{x}$ is not really my superior with respect to $B x^{\prime}$. But since I know of my own epistemic weakness compared to those philosophers, I also strongly believe that I must be mistaken in some of $\mathrm{S}_{1}-\mathrm{S}_{20}$.

Of course, one might hold that the solution to the preface paradox is not that one can have justified inconsistent beliefs that are known by one to be inconsistent. But even if that is the proper solution to the preface paradox, I suspect that the disagreement paradox is relevantly different from the preface paradox. In the latter, one believes $B_{1}-B_{20}$ and has no strong particular reason for disbelieving any one of $B_{1}-B_{20}$. Instead, one just has a reason-one's fallible track record-for believing the negation of the conjunction of $\mathrm{B}_{1}-\mathrm{B}_{20}$, along with the negation of any other large conjunction of one's beliefs. But in the disagreement case one has a good particular reason to reject each of $B_{1}-B_{20}$ : for instance, $B_{1}$ is a proposition about phenomenal consciousness, David Chalmers and Ned Block are experts on phenomenal consciousness, I'm not as expert as they are on the topics involved in the proposition (recall the conditions on epistemic superiority), and they firmly disagree with me. The fact that Chalmers and Block disagree with me on $B_{1}$, combined with the fact that they are my epistemic superiors on the topics relevant to $B_{1}$, very strongly suggests that there is good evidence $E$ against $B_{1}$ that I've missed or failed to appreciate. Upon learning their opinion I receive new and strong evidence that there is strong evidence against my belief $B_{1}$ that has escaped me. In my judgment, this is the key relevant feature separating the two cases. In the preface paradox case, all I have is the general consideration of my fallibility, which counts as relatively weak evidence that there is good evidence against my philosophical belief $\mathrm{P}$ that has escaped $\mathrm{me}^{21}$ In the disagreement case I have excellent evidence (the expertise and particular opinion of Chalmers and Block) that there is excellent evidence (it is probably excellent because it convinced Chalmers and Block) against my philosophical belief $P$ that has escaped me.

I don't want to dismiss the 'Well, this case is special in that the superior has just screwed up, or maybe he's not my superior after all when it comes to this specific issue' strategy entirely. When I read an oped in the New York Times that is written by a columnist I respect, I may justifiably think 'She thinks P on the separation of Church-State issue; I have thought $\sim P$ for many years now; so I guess she isn't my superior on that issue'. This makes the strategy criticized above look applicable. But in reality, although I may have a great deal of respect for the columnist, I never thought she was my epistemic superior on that issue, and that means that the epistemic renegade problem hasn't even come up. In fact, I think

\footnotetext{
${ }^{21}$ However, if one has excellent evidence that one's philosophical judgment is horribly unreliable, then one should give up most of one's philosophical beliefs_-especially those that put one in the Epistemic Renegade Situation.
} 
that regarding virtually any controversial issue in morality or politics, I have very few if any epistemic superiors writing in major newspapers in the world today. I don't think this is arrogance. I judge these people to not be my superiors because I hold that on virtually every controversial issue in morality or politics I'm significantly more careful, unbiased, reflective, and objective than they are. My IQ is sometimes lower than theirs, I'm often much less informed than they are on the uncontroversial issues pertinent to the controversial ones, I have often put less thought into the issue, and I definitely have my unreasonable biases and prejudices. But I still come out much better than them on a whole stack of epistemically crucial features. This has absolutely nothing to do with me specifically; it's a benefit of training such as that found in philosophy coupled with political discourse's relative lack of concern with evidence or rationality.

Despite all those arguments I just gave, I think the renegade can blamelessly hold, on at least some particular occasions, that the superior must have made a mistake somewhere or run into some misleading evidence-as long as the renegade has never thought about the consequences of this idea when applied generally. Keep in mind that although our renegade is reflective, she typically doesn't spend a great deal of her time thinking about the epistemic consequences of philosophical disagreement. Often enough, one's belief is reasonable and blameless even though a moment's reflection will make one seriously blameworthy if one retains the belief; that's why the phrase 'fragile blamelessness' is apt. (For instance, I might think that it's perfectly clear that in Tyler Burge's famous thought experiment for content externalism the medical doctors believe that arthritis is painful, even though it's controversial whether the protagonist of the thought experiment, who doesn't know that arthritis is inflammation of the joints, has that belief. My blameless belief: it's uncontroversial that the doctors have that arthritis belief. Even though my belief is blameless, if someone shouts 'Eliminative materialism!' I should give up that belief, supposing, somewhat counterfactually, that I have significant numbers of epistemic superiors who accept eliminative materialism and the other "exception" cases don't apply.) Something similar may hold in the renegade case: her explanation of why she is sticking to her guns is reasonable even though a moment's reflection will reveal its general inadequacy. Unfortunately, it takes very little reflection to see that when applied generally the upshot is that the people one thought to be one's superiors keep ending up to be one's inferiors, and it doesn't take nonstop or sophisticated reflection to see how implausible that is. That is why I think this maneuver won't often save us from the charge of blameworthiness.

Fourth and last species: extreme reliability. I am at a restaurant with friends. Joe gets the bill and says that with tip the total is $\$ 288$. We decide to split the bill evenly among the six of us. If I quickly do the math in my head, announce the answer $\$ 48$, but then Joe says he got the answer $\$ 46$, I will suspend judgment, as I should (cf. Christensen 2007). Part of the reason: I know that I did the calculation quickly in my head, and I know that that method isn't terribly reliable for me. So it's easy to tell the story in such a way one should suspend judgment. But we can also tell the story in such a way that one shouldn't suspend judgment, or so it seems to me (and Christensen would agree). Suppose I actually worked out the calculation on paper, doing the long division neatly, fully, carefully, and to the first couple decimal places. I also know that I'm fully sober, not sleep deprived, quite alert, etc. Up until the point at which Joe announced ' $\$ 46$ ', I would have insisted that Joe is not only just as generally capable 
as I am when it comes to long division but that he is just as likely as me to get the right answer this time around-especially since I see that Joe is also slowly doing the calculation on a piece of paper and I have every reason to think that he's just as sober and alert as I am.

But after he announces his answer I'm not going to suspend judgment, and I don't see anything odd about that. As soon as he announces his answer I will probably have just a few obviously relevant and contending explanations in front of me: (a) despite being perfectly sober, alert, and doing the calculation quite carefully, I made an error; (b) despite seeming to be perfectly sober and alert, I'm either drunk or very sluggish; (c) despite my initially thinking that Joe is just as alert and sober as I am, he actually isn't, or he has some other cognitive problem that's currently interfering with his ability to do long division. (Naturally, there's also the explanation that he is playing a joke on me, and thus isn't really disagreeing with me at all, but let's assume that I have done whatever is needed to rule that out as extremely unlikely.) In a realistic scenario, I'm going to reasonably think that (c) is much more likely than the others because, after all, I don't know about his alertness, sobriety, and current cognitive functioning as well as I know of my own. Frankly, given that I feel perfectly fine in every way and I went through the problem with real care, I'm going to judge that it's more likely that he isn't really feeling up to scratch and as a consequence has made a mistake of some kind. I'm not privileging myself in this judgment; I'm merely going by the impersonal odds. Such a judgment might be incorrect, but it's hardly unreasonable! After all, it's a very simple math problem. When he counters me with 'But I'm fine! I'm perfectly sober and coherent! Really!' I am going to guess that he's really trying to save face, or he is unwittingly fooling himself. I know that I'm perfectly well; in any realistic case I will not be capable of being as certain that he is perfectly well.

It's crucial to realize that in making this judgment on my behalf I'm not treating myself differently from how I'm treating J oe; I'm not engaging in some first-person bias. Suppose the situation had been slightly different: I haven't seen the bill, I have watched Joe and M oe do the calculation with equal care and thoroughness, and I have seen that Joe thinks the answer is ' $\$ 46$ ' while M oe thinks it's ' $\$ 48$ '. If my evidence that $\mathrm{M}$ oe is sober and alert is significantly better than my evidence that joe is sober and alert, then I'm going to conclude that M oe is right and Joe is wrong (or, at least, I'll put significantly more weight on M oe's word than Joe's word). Now if we let M oe $=m e$, we have the original situation described above.

I think the same result holds for a case Feldman claims to offer clear support for his view (2006). You are in my office and we both look out on the quad. I seem to see perfectly well a person there with a blue coat on, and so I tell you that I see such a person. You have a good look at the quad but then say there is no person there with a blue coat on; in fact, there's no one there at all (so we are not just arguing over a borderline case of blueness or coatness or personhood). I know that I feel perfectly fine and that the scene I seem to be seeing looks utterly normal. Feldman says, rightly, that after encountering your opinion I should conclude that something strange is going on. But he also says that I should suspend judgment on whether there is someone in the quad with a blue coat on. This strikes me as implausible. Obviously, I will initially think there is no disagreement, and you are pulling my leg. If I can somehow rule that possibility out (it is not child's play to tweak the example to make this task 
realistically doable), then I will be faced with two obvious possibilities akin to (a)-(c) from the restaurant case: (d) I've temporarily lost my mind, even though I feel perfectly fine and everything seems utterly in order visually and with my reasoning skills, or (e) although you appear to me to be functioning perfectly well, you are functioning quite badly right now and your reports to the contrary are just plain false. Just as in the restaurant case (e) will strike me as more likely than (d), and I don't see anything unreasonable in my making that judgment.

Even if all of what I just argued regarding the extreme reliability case is true, I wonder how much application it has in philosophy. How often do we form our philosophical beliefs via processes we know to be extremely reliable-like in the arithmetic case? The answer depends in part on what counts as a philosophical belief. I think I have a laptop, and I formed the belief in what can be considered for the sake of argument an extremely reliable process, but I know that some metaphysicians think that there are no laptops-metaphysicians who are my epistemic superiors when it comes to the metaphysics of composition, identity over time, and the like. (Thus, this species connects up with the skeptical argument given at the end of this essay.) However, whereas in the restaurant and quad cases the disagreeing parties agree on the extreme reliability of sense perception and long division but disagree on who made a mistake in the particular execution of the process, in the philosophy-againstcommonsense cases there is disagreement concerning the reliability of the processes themselves.

In the remainder of the essay I will do three things. First, I'll argue that the renegade situation occurs less often than one might think (in philosophy). Second, I'll present and try to counter arguments against my Unfavorable Thesis. Finally, I will show how to use the Unfavorable Thesis to generate a novel and good argument for a novel kind of radical skepticism.

\section{Reasons Why the Problem is Rarer in the Philosophical Realm than You Might Think}

By acknowledging and then setting aside the four species for which it is plausible that there is no blame in being a renegade, we have diminished the number of blameworthy instances of the Epistemic Renegade situation. There are other facts that do the same thing.

Even though one might repeatedly assert and defend $P$, with all sincerity and honesty, one may not actually believe $\mathrm{P}$ - to any degree at all. For instance, I could be a presentist (roughly: only presently existing and atemporal objects exist in the core sense of existence) even though I don't believe that presentism is true. That may seem odd to a non-philosopher, but it will be familiar to any professional philosopher. My commitment to presentism might well fall short of belief. I may defend it, call myself 'a presentist', and suspect that the current public evidence is in its favor, but I need not believe it's true. There's no requirement that I be sure enough to actually believe it. So there is no epistemically blameworthy belief in presentism because there is no belief in presentism even in the presentist. ${ }^{22}$

\footnotetext{
${ }^{22}$ This case highlights a common sense of 'disagreement' that I am ignoring: I disagree with you (in this alternative sense) if I've argued in several articles for P while you have argued in several articles against
} 
Related to this is the fact of conditionalized philosophical belief. In an ordinary philosophical conversation I may say, 'We know a priori that $P$ ', but I need not believe exactly that. If you challenged me with the work of superior philosophers who after thorough, fair, and competent reflection came to think that there is no a priori knowledge, I might, depending on the context, correctly declare your argumentative move out of bounds. In doing so, I wouldn't be conceding that I'm wrong or asserting that those experts are wrong. I'd be saying that I wasn't really disagreeing with them in the first place. All I really believe is something like this: if the notion of apriority is coherent and has applications in mathematics, say, then we know a priori that $P$. In fact, I might think that there is no apriori knowledge whatsoever (in fact, I might be a complete skeptic about knowledge). Philosophical discourse is peculiar in this manner, for in ordinary life when we sincerely assert $P$ we tend to believe $P$, full stop. But on many-not all-occasions in philosophy, our sincere utterances don't match up with our beliefs in such a neat way.

This phenomenon of conditionalized philosophical belief is relevant for three reasons. First, it shows that even though I say $P$ and my superiors say $-P$, very often I'm not really disagreeing with $-P$ (and in many cases those experts aren't disagreeing with P). Second, a big portion of my philosophical beliefs is conditionalized. Third, I'm often not aware of superiors who disagree with my conditionalized belief. I really and truly believe that if $\mathrm{Q}$, then $\mathrm{P}$, but even though I'm perfectly aware of some philosophical bigshots who say that $-P, I$ may be roughly familiar with the state of the art and yet unable to name anyone who thinks that $\mathrm{Q}$ is true and $\mathrm{P}$ is false-which is to say, I may be unable to identify any superiors who genuinely disagree with me. In fact, when I believe that if $\mathrm{Q}$ then $\mathrm{P}$ and I learn that Kit Fine, for instance, says $-P$, I may legitimately wonder whether what he really holds is something of the form 'If $R$ then $-P$ ', where there is no simple relation between $Q$ and $R$. The upshot is that the Epistemic Renegade problem is significantly rarer in philosophical discourse than one would think.

Thus, there are two ways (no belief, conditionalized belief) in which evidence that the Epistemic Renegade situation is present can be misleading. In addition, often when the situation really does arise, so I believe $P$ and my superior believes $-P$, my belief is held so weakly that the epistemic sin, if any there be, is significantly lessened. Philosophical beliefs are typically held with a degree of confidence much lower than that for our ordinary empirical beliefs. For instance, I believe that Ronald Reagan was President of the US. If confronted with the question, 'What is the percentage chance that you're wrong about that?' I would reply with 'Nearly $0 \%$.' I also believe (let's pretend) that belief content doesn't supervene on one's intrinsic physical properties. I really do believe it, instead of merely being somewhat inclined to believe it or having any other weaker pro-attitude regarding that proposition. But if confronted with the same question, 'What is the percentage chance that you're wrong about that?' I would reply with 'Oh, I don't know; maybe roughly 20 or 30\%.' I'm just not anywhere near as sure. I'm about 70 or $80 \%$ sure that externalism is right; whereas I'm virtually $100 \%$ sure Reagan was President

P. But this kind of disagreement is weak and epistemically uninteresting, as it need not involve any belief in the truth or falsity of P. 
(the only remotely realistic possibility I can think of is that through some unnoticed glitch in procedure, he never legally became president). The 70 or $80 \%$ is enough for belief, at least under one common notion of belief.

It is due in part to the relative weakness of my philosophical beliefs (compared to beliefs such as the Reagan one) that they can be (at least nearly) epistemically upstanding even though knowingly held in opposition to philosophers who I admit are my philosophical superiors. The lower the degree of belief in $P$ the lower the hurdle for being epistemically upstanding in continuing to believe $P$ in the face of recognized disagreement with recognized epistemic superiors. Or so it seems to me!

However, the above considerations don't go far enough. There are two reasons why. First, many philosophers have in fact a very high degree of belief in philosophical claims they know are disbelieved by some of their recognized epistemic superiors. Second, one might still ask how I can believe P even to a small degree when faced with contrary opinion that I recognize as coming from epistemic superiors (and I'm not in any of the four exception cases). The "philosophical gods" say -P; how can I believe P at all when I know full well that they are my philosophical superiors and have worked on the question whether $\mathrm{P}$ much longer and more expertly than I have? ${ }^{23}$

\section{Attempts to Justify the Reflective Epistemic Renegade}

I think my main claims are not terribly unkind to us: if they are true, many of us aren't epistemically horrible even if often blameworthy in virtue of being reflective epistemic renegades. However, there are reasons for thinking that I have not been kind enough-arguments for thinking that some of my central claims and assumptions are false. In this section I consider ten arguments against my Unfavorable Thesis. It seems to me that the arguments fail. However, each of them throws light on the issues and so makes a positive contribution to that extent.

First argument. If I do a complete and fair and professionally competent investigation into whether $\mathrm{P}$ is true, then I can hardly be epistemically blameworthy; for how much more could I be reasonably expected to do?

However, in some sense there are no complete investigations for most interesting topics in philosophy. And even if there were some of kind of professionally relative notion of completeness that is frequently met (e.g., careful, thorough, and competent investigation of all or most of the clearly relevant literature to date), to assert that meeting the standard of professional completeness suffices for blamelessness is to just beg the question. We want a robust explanation of why we are blameless, assuming we are blameless. The Epistemic Renegade problem arises when we first see that competent, thorough, careful

\footnotetext{
${ }^{23}$ Finally, there are all the cases in which there is no disagreement because of equivocation, polysemy, inadequate grasp of concepts, or lack of truth-value. I won't comment on their frequency, although I can say that I think they are more common than it may appear.
} 
professionals who have done well by professional standards still seem epistemically blameworthy in continuing to believe $P$ when they recognize many epistemic superiors with respect to $P$ who believe $-P$. And of course in most cases where we are in the Epistemic Renegade situation we haven't done a professionally complete investigation!

Second argument. Philosophy is so hard that even the geniuses are very fallible and so shouldn't be trusted; thus, I'm epistemically blameless in disagreeing with them.

I think the point about deep fallibility is probably true; the philosophical gods are definitely not philosophical gods. If they were, presumably they would agree with one another pretty often and we could take them at their word. Hero worship is a big mistake in philosophy-at least it is when accompanied by belief in the hero's views in spite of being in the Epistemic Renegade situation. However, the fallibility point only suggests that I-the mere mortal quite a bit distant from genius-am even more unreliable than they are. The fallibility point can amount to a decent argument if developed into the third exception species from section 3 (fragile blamelessness), but mere fallibility of superiors provides no excuse.

Often I will be in a position of knowing that some of my epistemic superiors are not merely fallible but massively mistaken on some topic. For instance, as I understand it at least one of Chalmers and Dennett must be extraordinary wrong in their conclusions about phenomenal consciousness. If I just pick and choose my assertions from the two of them, I will probably end up more reliably right in my conclusions than at least one of them (depending on how reliability is calculated); and I know this. However, I don't think that this fact adversely affects my reply to the second argument. There is a lot more to a person's philosophical view on a subject than the view's conclusions. Although I won't defend it here, I suspect that there is actually a great deal of agreement among experts (regarding their areas of expertise) in philosophy, even if it isn't easy to state the agreed-upon theses. For instance, if asked to write a book for sophomores and juniors regarding the important questions, theories, concepts, examples, and arguments regarding their area of expertise, I suspect that most experts would make a lot of the same choices and assertions (perhaps even people like Dennett and Chalmers, to take two very different philosophers of mind). Thus, when we relativize to area (philosophy of mind, epistemology, etc) it seems to me that I won't be as reliable as Chalmers or Dennett on consciousness issues-even though I may even know that I'm probably more reliable than at least one of the two regarding my conclusions on consciousness (see also footnote 29 on being more reliable than the recognized superiors).

Think of the scientific analogue. Physicists A and B have very different views on quarks vis-à-vis gluons, say. If forced at gunpoint to write down their top ten conclusions on quark-gluon theory, their lists would be utterly disjoint and mutually contradictory. Even so, I know perfectly well that both A and B are internationally recognized experts on quark and gluon theory. Suppose I am a physicist who specializes in low-temperature physics. I know that either A or B is utterly wrong in their top-ten list, but this isn't going to help me figure out what to do in the renegade situation with respect to either $A$ or B. 
Third argument. Suppose that I hold that P and I'm frustrated because I just learned that Chalmers, Fine, Williamson, and Kripke all have held and argued for $-P$ for years and for a variety of published reasons. The Epistemic Renegade problem has come up. I then consol myself with the information that virtually no one disagrees with my belief in Q. Everyone in philosophy who is a peer or superior agrees with me on $Q$ (the mind boggles!). But then I reflect on the fact that it's merely contingent that no superior disagrees with me regarding $Q$. I realize that I'm just lucky that no actual contemporary superiors challenge my belief in Q. I could have had just the evidence I actually have, and had acquired it in the very same fashion, and yet I could have been surrounded by several recognized epistemic superiors who believe $-Q$. I don't mean: in some logically remote world; I mean that the possibility is quite realistic. After I've gone through this very real possibility in my mind, am I epistemically blameworthy if I don't give up my belief in Q-or at least lower my degree of confidence in Q? And since that would mean that virtually every philosophical belief of mine is blameworthy, which is quite unlikely, there must be something wrong with the idea that being in the Epistemic Renegade situation, with the actually existing epistemic superiors, makes one's belief blameworthy (cf. Kelly 2006).

I think this argument fails. The reason that actual disagreement with admitted experts counts against my belief is twofold. First, I believe that Q is actually true. Second, actual disagreement with experts makes it highly probable that there's actual good evidence for the actual truth of $-\mathrm{Q}$. We care what the experts think in part because, being experts, their belief on the matter will be informed by the evidence, broadly construed. More specifically, long-term endorsement of a claim X by multiple experts for multiple reasons that have been gone over in public is an excellent indicator of good evidence for $X$; it's also an indicator, albeit less impressive, that the overall available evidence concerning $X$ favors $X$ 's truth. So, the actual disagreement counts against my actual belief. When I believe $Q$, I believe that $Q$ is actually true (even if I believe Q is necessary), and I worry about the experts disagreeing with me because I know that there probably is some good evidence against $Q$ that's actually lying around somewhere. Thus, I care about possible disagreement only if it provides some reason against Q's actual truth.

Now consider a real-life thesis. Suppose $Q$ is content externalism and pretend that none of my many actual contemporary epistemic superiors with regard to $Q$ believes $-Q$. Recall that in order for merely possible expert endorsement of $-Q$ to put any pressure on my belief, such endorsement must indicate that Q might actually be false. But can I imagine a world just like the actual world in which a significant number of my superiors have good reasons for endorsing -Q-reasons that exist in the actual world as well? Not necessarily. I can of course picture in my mind a bunch of my actual epistemic superiors giving talks and writing papers defending content internalism; I can do this with any claim whatsoever. But when I ask myself, 'Yes, but might they be doing so for good reasons that hold in the actual world as well?', it depends on the sociological facts concerning the claim involved. When it comes to some claim that none of my many actual epistemic superiors (or peers) endorses, I have no good reason to answer the question affirmatively - provided that the actual, contemporary community of professional philosophers is huge (especially the number of my epistemic superiors regarding Q) and has investigated Q thoroughly. But that condition will be satisfied for most any of my philosophical beliefs that I'm aware 
of being denied by epistemic superiors, given that I'm a philosopher of ordinary abilities who doesn't have revolutionary ideas (sigh). ${ }^{24}$

The third exception species from section 3 (forgiving percentages) comes in here as well. As mentioned in that section, I'm not blameworthy if my actual agreeing superiors outnumber my actual disagreeing superiors 10 to 1 (assuming the disagreeing contingent aren't known by me to be the superiors of the agreeing contingent). Thus, if the merely possible disagreeing superiors are supposed to suggest that I'm blameworthy, they can't be outnumbered 10 to 1 by my merely possible agreeing superiors. But how on earth am I supposed to figure out the ratio among merely possible people (especially when the numbers are infinite)? Eventually I'm going to be forced to examine the actual world: how many superiors do I actually have regarding P; how many actual arguments regarding $\mathrm{P}$ have actually been thoroughly examined, etc. Thus, just like before my attention has to go to the actual world.

One could counter by arguing inductively: history has shown that for virtually any philosophical claim, even if no geniuses believe it at some point in history (or even during a lengthy period), it's just a matter of time before a significant number of such geniuses endorse it-in the actual world. Epistemicism is a good example, as are many contemporary positions in analytic metaphysics. But I suspect that most people will think this inductive argument just isn't very strong, at least not today and for most of the topics most of us work on. There are many extremely intelligent and well-trained professional philosophers doing research now, and just about every remotely plausible view gets worked through by someone at some point-at least, and this point is crucial, this is true for any view that I might stumble upon (again, given my limited imagination as an average philosopher; and most of us are average philosophers). For instance, if radical monism, the claim that there is only one concrete thing, is still virtually without followers who are my actual contemporary epistemic superiors, then although the inductive argument gives some reason to think that there is some actual evidence in its favor, this reason is weak. Not zero, but small enough to not harm me as a reflective epistemic renegade. So the claim stands: only actual disagreement provides any powerful reason for blameworthiness. This does away with a crucial premise in the third attempt to justify being a renegade.

Fourth argument. Suppose you know of some argument for $\mathrm{P}$ that strikes you as excellent. There is a nearly irresistible feeling of being right about an argument. One experiences a real phenomenological feel in this kind of situation, a kind of intellectually charged quale. Perhaps we should know better, at least after some experience, than to conclude that the argument is compelling, but when one is basking in the glow of an argument for $P$ that repeatedly strikes one as sound, it is awfully hard to continue to appreciate the cold, hard truth that others-including epistemic superiors-have experienced the very

\footnotetext{
${ }^{24}$ Obviously, if there are many superiors who believe $\neg \mathrm{P}$ while I believe $\mathrm{P}$, and they all die in a hurricane that hits a conference, then the Epistemic Renegade problem is still in force because their recent and actual endorsement of $\neg \mathrm{P}$ shows that there is actual and contemporary evidence for $\neg \mathrm{P}$. The superiors don't have to hang around in order to threaten my belief.
} 
same feeling when constructing arguments for the opposite conclusion. Given how difficult, psychologically, it would be to sit back, after experiencing that "glow" about one's argument, and temper one's judgment with 'But of course geniuses $X, Y$, and Z say -P; so I'd be foolish to just go along with the glow', to some extent we are reasonable in concluding $P$. It's almost as though the glow precludes from serious epistemic processing one's knowledge that there are epistemic superiors who disagree. One's natural psychological propensities simply force one to go along with the glow. Although we have some power over our doxastic inclinations, it's limited. To demand that we resist the force of glow experiences is to make epistemic blamelessness too demanding.

However, this won't do. Perhaps we can be excused for getting carried away with our own reasoning while in the thick of it. "Hey! My new argument shows why Williamson's epistemicism is wrong after all!" I personally find myself on occasion temporarily thinking things of the form, 'Well, only an idiot would think -P given any competent assessment of the available evidence' even though a moment's calm reflection would force me to admit that in many cases there are many non-idiotic believers in $-P$ who are aware of all that evidence. But the question at issue in the Epistemic Renegade problem is whether we should continue to believe that Williamson is wrong - even when the glow is no longer occurrent. By then one should sober up a bit, at least once one has reflected on the odds that one's argument is the refutation of Williamson's claim X (and keep in mind that according to our characterization of 'epistemic superior' Williamson would have to be familiar with your argument).

Fifth argument. Even if there weren't these psychological propensities to follow the glow - or, more generally, to follow one's intellectual abilities and deliverances-what else would we do in forming beliefs? What's the alternative? It won't do much good to just follow the experts, because they almost always disagree (and we often can't figure out what they really believe anyway). More to the point, if I didn't follow my philosophical inclinations and abilities, how could I even be a philosopher who does research? How would I proceed? I have to go along with my own judgment.

There is some truth in this argument. In some sense, I simply must follow my inclinations, arguments, and glow experiences-even when they tell me to follow someone else or suspend judgment entirely. My Unfavorable thesis is, roughly, that when (a) your judgment tells you that $P$ is true, but (b) your judgment also tells you that a group of epistemic superiors on the relevant issues all hold that P is false, then unless some moderately peculiar circumstances hold (e.g., forgiving percentages), you should give up or at least significantly weaken your belief in $\mathrm{P}$. But this is consistent with the event of your giving up $P$ being a case in which you are "going with your judgment and trusting your instincts", and not going against them. Part of my judgment/instinct is (b); so the process of "going with my judgment" is not just going with (a) and ignoring (b). In some sense, to trust oneself may not only be permissible but necessary, but it need not involve belief in the conclusions one is led to when one ignores the opinions of others. In addition, we saw earlier (when discussing research and action) that giving up on $\mathrm{P}$ need not mean that one stops relying on it in one's philosophizing. Is there any good reason why an experienced philosopher can't produce good philosophy with real passion and interest and yet often refrain from belief in philosophical claims? Can't we follow our own noses and yet refrain from belief-when we see that recognized epistemic superiors deny those beliefs? Is there any good reason why we must "land" 
on the conclusions of our arguments and basic philosophical inclinations, thereby believing them, instead of just "hovering" over them and seeing where the arguments have led us? ${ }^{25}$ I'm tempted to say that although we can to a certain extent let our abilities, inclinations, and glow experiences guide our research-we simply must act, and in making the decision we are trusting ourselves-in doing so we really should withhold belief and be more cautious once we discover or remind ourselves that some of our recognized epistemic superiors disbelieve the claim we're inclined to believe. "Hovering", with its suspension of belief, is an obvious and attractive alternative to belief. ${ }^{26}$

Sixth argument. As a matter of brute fact, our practice in philosophy is to keep our beliefs, even in the Epistemic Renegade situation. That's the way it's been done around here for centuries. PhD students are encouraged to formulate and defend their own philosophical opinions (although this was false a few centuries ago), and I don't suppose that anyone criticizes them for disagreeing with David Lewis, Timothy Williamson, and the rest even when the students are wise enough to admit that those philosophers are their superiors on the relevant topics. So, how can we blame individuals who persist in this epistemic practice? Perhaps from some God's-eye perspective our profession is blameworthy for engaging in this practice, but it's hard to believe that the average philosopher is blameworthy in just going along with the generally accepted way of doing things-a practice that has been in force for centuries. Surely the PhD student isn't blameworthy, and wouldn't it be asking too much to demand that the average professor go against the system in order to escape blame? Perhaps withholding belief when on the cusp of the Epistemic Renegade situation is praiseworthy, but it's a stretch to say that failing to do so is blameworthy.

I don't agree with that argument. For one thing, I don't think that is our practice. As stated in section 4, I think many of us avoid the situation for many of the philosophical claims we're attracted to and defend. I realize that it looks as though we fall into the situation almost constantly, if one examines just our publications and presentations. But since it's tedious to include in one's writings or talks dozens of clauses akin to 'It seems to me', the lack of belief in essay theses is often difficult to detect-for outsiders anyway.

\footnotetext{
${ }^{25}$ I think there is such reason in many cases outside of theoretical philosophy. One's weakly held beliefs don't engage action nearly as well as one's strongly held beliefs. It's even worse when I have to act on the assumption P when I don't believe it (even weakly) but merely think it has a real chance at being true. So in order to act one might, psychologically, need belief instead of some doxastically weaker mental state. But I don't see much reason for this when it comes to my opinions on content externalism, fourdimensionalism, presentism, evidentialism, Millianism for belief contexts, and many other philosophical views. Thanks to Allan Hazlett for illumination on this point.

${ }^{26}$ It should be clear at this point that I am not saying that suspension of belief is always the option to take; don't forget the Favorable Thesis defended in section 3.
} 
In addition, the sixth argument is slightly ironic. Everyone agrees that philosophy is a highly individualistic enterprise, despite our recent embrace of the method of working on issues as a large group. We aren't supposed to be epistemic sheep; we aren't supposed to just take something on Kant's authority, for instance. We are supposed to bushwhack our own way through the philosophical thickets. When I hear elaborations of the sixth argument they are often peppered with appeals to the individualistic nature of philosophizing. And yet, the defense of our continuing to believe $P$ when we're fully aware of how Lewis, Williamson, and Chalmers have each believed and argued for $-\mathrm{P}$ for years, comes to this: 'Well, proceeding in an individualistic vein is what everybody does'?

I think the point about individualism is right: we are supposed to follow our own noses, regardless of where they lead us. (Recall the remarks about the research renegade made earlier.) But we are also supposed to follow the evidence when we have it staring in our faces. And if we know that a bunch of people we know to be our epistemic superiors believe $-P$, then we have truly excellent evidence that there is good reason to refrain from accepting $P$. I realize that in some situations we have good reason to think that that "truly excellent" evidence is misleading; I have described some of those situations in section 3. However, those situations are exception cases. Given that we are blameworthy if we fail to follow evidence actually recognized as evidence, I think in most cases we would be blameworthy in the Epistemic Renegade situation even if it were our profession's practice to not avoid the Epistemic Renegade situation.

I suppose that if one just can't stop oneself from retaining beliefs in the Epistemic Renegade situation, then one is less guilty. But not absolved entirely. I want to say: if you're a professional philosopher who's been around the block and who falls into the Epistemic Renegade situation, then you should have the ability to work productively and yet withhold belief-at least when it comes to philosophical beliefs. If you don't have that ability, then you're epistemically blameworthy; it's a skill you should have obtained by now.

Seventh argument. It's plausible that if you genuinely and justifiably believe that you have come up with an entirely new argument for $\mathrm{P}$, you justifiably believe that almost no one else has even considered your argument, and your argument has recently gained some expert acceptance (via some journal referees for instance), then you are less blameworthy than someone who believes $P$ on the basis of considerations they know full well have been thoroughly digested by the experts who believe $-P$. Surely that's right! And since the envisioned scenario is relatively common as well, this fact will let many renegades off the hook.

There are four problems here. First problem: I suspect that although the antecedent of the argument's main principle is certainly satisfied on some occasions, in most cases in which the Epistemic Renegade problem has been generated the antecedent is true only if we omit the occurrences of 'justifiably'. We may justifiably believe that our argument is novel, but until it has passed through the gauntlet of peer review (and I don't mean just a referee or two, even at the most respected journals and academic presses), we rarely have much reason to think it's very good. It looks great to you, and the referee and editor of such-and-such journal liked it, but let's not get carried away. Second problem: in many other 
cases we'll have some or other articulated reason behind our endorsement of $\mathrm{P}$-when challenged about our opinion we have something to say in response-but we are fully aware that when formulated in print our reasons would hardly amount to something even publishable. Third problem: in still other cases we'll fully admit the hard truth that we disagree with David Lewis on some metaphysical matter even though we don't pretend to have any argument that Lewis (and Ted Sider, Kit Fine, etc.) just haven't had the pleasure of seeing. So, the renegade problem certainly hasn't gone away. Finally, the argument is a non sequitur: in the envisioned circumstances your superiors don't have your new evidence (viz. your new argument), and this means that the people who used to be your epistemic superiors no longer have that status.

Eighth argument. Reiterating my reasoning regarding the epistemic situation of the renegade leads to interesting thoughts, some of which may suggest that my claims are defective in some way. Imagine a situation with all the following idealized features (it can be made moderately realistic). You have 100 epistemic superiors regarding P. Of these, 80 are what I'll call mutual negative peers: for any two of them, neither is the superior of the other. The remaining 20 are superiors of the 80 and are themselves mutual negative peers. Each of the 100 knows of the two groups and knows which group they are in. You also know of the superiority and negative peer facts just mentioned. On Monday night almost no one in the group knows what the others think regarding $P$. (This is unrealistic of course: we are the ones writing the essays discussing $P$ that each of us reads. But suppose none of us had spent much time reflecting on who thinks what regarding P.) On that M onday night a poll is taken of the 100 philosophers, asking them for their degree of confidence in P's truth. Each of the 80 responds truthfully with ' $50 \%$ sure'; each of the 20 responds truthfully with ' $90 \%$ sure'. That night your response, if anyone had bothered to ask you, would have been ' $50 \%$ sure'. The poll is published the next day, Tuesday, at noon, and all 100 philosophers read it. So do you. That afternoon you think to yourself 'Gee, those 80 super-folk agree with me, but those 20 super-duper-folk are much more confident in P. I'll bet they know something the rest of us don't. Now I'm more confident in P than I was before. If anyone asks, my degree of confidence is $70 \%$ '. ${ }^{27}$ But each of the 80 philosophers went through similar reasoning that afternoon after reading the poll results. Each of them thought 'Gee, those 79 peers agree with me, but those 20 superiors are much more confident in P. I'll bet they know something the rest of us don't. Now I'm more confident in $\mathrm{P}$ than I was before. If anyone asks me again, my degree of confidence is $70 \%$ '. That night the pollsters call the 100 philosophers again and ask them the same question regarding $\mathrm{P}$ that was asked on M onday night. Everyone answers truthfully: the group of 80 responds with ' $70 \%$ sure' and the group of 20 respond with ' $90 \%$ sure' (so the latter folk don't change their minds). The new poll is published the next day, Wednesday, at noon, and all 100 philosophers read it. So do you. Now you see the new results: the 80 say ' $70 \%$ sure' and the 20 say ' $90 \%$ sure'. What are you supposed to do with this new information? And what is the group of 80 supposed to do with the new information?

\footnotetext{
${ }^{27}$ I don't think there is a unique confidence level dictated by rationality plus evidence, even if there is one dictated by perfect or maximal rationality plus evidence.
} 
It might be thought that the defender of the Unfavorable Thesis should say that these philosophers should increase their confidence levels again. Perhaps the group of 80 should increase their confidence levels to $80 \%$. And if we reiterate the process again, the confidence levels should go up again. And of course that seems dubious!

But nothing I've tried to say in this essay leads to this outcome. For instance, although my Unfavorable Thesis ('If one is a reflective epistemic renegade with respect to one's belief in P, and one isn't in any of the four exception cases, then one's retaining $P$ is blameworthy') is intended to recommend that when one gets into an epistemic renegade situation one should alter one's confidence toward that of the superiors, when the second poll comes out one is not in a new epistemic renegade situation. At least, that's how I have been conceiving 'epistemic renegade situation'. The first poll gave you new and good evidence that suggests that $P$ is more probable than you originally thought. But the second poll doesn't do that. All it does is show that the 80 philosophers followed their new evidence (supplied by the first poll) roughly as anticipated. One should alter one's opinion in response to information about the opinions of epistemic superiors only if that information gives one new and significant evidence regarding $P$. So, with the second poll you have no additional good reason for further increasing your confidence level in P. ${ }^{28}$

It must be said that the second poll could supply you with additional good reason, though, depending on the details of the second poll and how you interpret it. Suppose that in the second poll it was revealed that each of the 80 moved their confidence levels all the way to $90 \%$. And suppose I knew full well that each of those 80 philosophers is a fiercely independent thinker (and perhaps they know that God is one of the 20). I would then strongly suspect that the group of 20 has some members who are much smarter than I originally thought on Tuesday (remember that I increased my confidence level to just $70 \%$ upon reading the first poll). Thus, the second poll might give me some relevant new information that should lead me to alter my confidence level once again. But in this example the regression ends here.

Ninth argument. Consider a third thesis, modeled on the Unfavorable Thesis:

Thesis (3): Suppose that if $S$ were to come to believe $P$, then $S$ would be a reflective epistemic renegade with respect to $P$ and $S$ would not be in any of the four exception cases with respect to $P$. Then if $S$ came to believe $P$, her holding that belief would be blameworthy.

Frank is a contemporary epistemologist who is initially attracted to thesis (3) but he has yet to make up his mind on it. He also knows that in his philosophical community a bunch of contemporary epistemologists think thesis (3) is false-epistemologists who are his recognized epistemic superiors when it comes to (3). He also knows that he isn't in any of the four exception cases mentioned earlier. So he knows both of the following:

${ }^{28}$ I discuss cases like this one in more detail in my Forthcoming. 
(i) If I come to believe (3) then I will be a reflective epistemic renegade with respect to my belief in (3) and I will not be in any of the four exception cases with respect to (3).

(ii) If (a) (3) is true and (b) if I come to believe (3) then I will be a renegade with respect to (3) and I will not be in any of the four exception cases with respect to (3), then (c) given my peculiar circumstances if I came to believe (3) my holding that belief would be blameworthy.

He knows (i) because he is familiar with his philosophical community, his place within it, and his own doxastic self. He knows (ii) because he sees it's a logical truth. Now (ii) is [(a) \& (b)] $\supset$ (c) and (i) is just (b). Thus, since Frank knows (b) and he knows $[(a) \&(b)] \supset(c)$, he can, if he puts this all together properly, conclude (a) $\supset(\mathrm{c})$ :

(iii) If (3) is true, then given my peculiar circumstances if I came to believe (3) my holding that belief would be blameworthy.

Now what is Frank supposed to do about (3)? We have already distinguished the reflective epistemic renegade from the reflective research renegade, noting the lack of reason to think the research renegade is blamew orthy. The reflective epistemic renegade with respect to $P$ is within her rights to assume $\mathrm{P}$ is true in her research; this applies to (3) just as well as any other philosophical principle. But this won't get us off the hook entirely. Say Frank is attracted to (3) and thinks that he should arrange his doxastic life in accord with it (as it implicitly recommends that he refrain from some beliefs in certain circumstances). But he knows that if (3) is true, then he would be blameworthy to believe it (i.e., he knows (iii)). How on earth can he rationally arrange his doxastic life around a principle that tells him that he'd be blameworthy to believe it? This looks pretty suspicious, which makes one think that (3) may well be false in Frank's scenario in which it is disbelieved by a significant number of epistemologists. But if it is false in that scenario, it is probably false in the actual world at the present time (perhaps such epistemic principles are relative to epistemic practices; so one has to be careful with the inference from ' $P$ is false in world 1 ' to ' $P$ is false in world 2 '). Finally, if thesis (3) is actually false, then my Unfavorable Thesis may be actually false as well.

That objection, which I dub the Self-Application Objection, looks good, although I think we can see that there must be something wrong with it. Consider again the extreme renegade from section 2 , who knows that 98 of his 100 superiors and 392 of his 400 peers disagree with him. I don't suppose anyone rejects this principle $R$ : if someone is an extreme epistemic renegade with respect to $P$, then her holding that belief $P$ is blameworthy. And yet, what if you were in a (admittedly weird) philosophical society in which you believed R, you had 100 recognized epistemic superiors regarding $R$, you weren't in any of the exception cases, and you found out that 98 of those superiors (who are fiercely independent thinkers) firmly believed that $\mathrm{R}$ is false? That is, what happens when $\mathrm{R}$ applies to itself? Running through the line of argument that Frank went through, you end up concluding this:

If $\mathrm{R}$ is true, then if I came to believe R my holding that belief would be blameworthy. 
If the Self-Application Objection shows that (3) is actually false, then since the two cases (i.e., (3) and R) are so similar it must show that $R$ is actually false. But $R$ is true in the situation envisaged, right? Moreover, I suspect it would be true in the actual world as well (this isn't to say that it's a necessary truth). So, there probably is something wrong with the Self-Application Objection, although this little argument isn't conclusive and doesn't tell us where the flaw is.

It's important to see that this problem applies not merely to (3), R, and the Unfavorable Thesis. If you accept any thesis $T$ of the form 'If such-and-such conditions obtain with respect to one's belief in $P$, then one should withhold belief in $\mathrm{P}^{\prime}$, then provided the antecedent of $\mathrm{T}$ can be true when $\mathrm{P}=\mathrm{T}$, then you have to deal with a version of the Self-Application Objection. The probability that some such principle T should be true gives us good grounds to think that there must be something amiss with the SelfApplication Objection.

Independent of those counterarguments, I think I have a more direct response to the objection. Consider again the conclusion (iii) that Frank has reached:

If (3) is true, then given my peculiar circumstances if I came to believe (3) my holding that belief would be blameworthy.

At this point Frank is faced with two interesting questions about (3):

(A) What position am I going to take with regard to (3)'s truth-value?

(B) Am I going to arrange my doxastic life in accord with (3)? That is, (3) implicitly recommends that one withhold belief in certain circumstances; am I going to act on that recommendation?

Before I try to answer those questions, let me make explicit the obvious point that one might not have any peers or superiors who disagree with one regarding (3). For instance, that's the way things are now; after all, almost no one has ever even considered (3). Or, one might be a top-notch expert with no peers or superiors who deny it, even though they have considered it. In such cases, one might be perfectly permitted to believe it.

Let me step in for Frank here, as I clearly have an attraction to (3) and I can imagine being an epistemic renegade with respect to (3). Yet, since I'm generally disinclined to believe highly ambitious philosophical principles (ambitious compared to many other philosophical principles), whether or not they put me in the epistemic renegade situation, I am also somewhat disinclined to believe (3). Furthermore, the Self-Application Objection makes me even more wary of (3). I see that (3) applies to itself, and I am reminded of various semantic and epistemic paradoxes that tend to go with self-applying principles. Due to these two factors (disinclined towards ambitious philosophical principles, wary of self-applying philosophical principles), I don't go so far as to believe (3). I withhold judgment. Not only 
do I answer 'I don't know' to 'Is (3) true?' but also to 'How much credence do you put in (3)?' That's my answer to $(A)$.

Let me make it clear that I'm not led to suspension of judgment in this way:

I can see the truth of the conditional C that if (3) is true, then I shouldn't believe it. I think (3) is true; that is, I accept C's antecedent. Thus, since I accept C as well as C's antecedent, I have to accept C's consequent: I shouldn't believe (3). So, I won't believe (3). I'll suspend judgment.

That looks incoherent. If I suspend judgment on a principle, any principle, it might be due to my following the recommendation in (3). But in the case at hand although I am suspending judgment on (3) I am not doing so because I'm following the recommendation in (3). I'm doing it for another reason entirely. I'm suspending judgment on (3) due to my long-standing commitment to the following rule of thumb:

If you are inclined to agree with a philosophical principle, but then you realize that it's pretty ambitious, worrisomely self-applying, and confusing (for you), then you should suspend judgment on it.

What about question (B)? Just to make the question live, suppose that before writing this essay I was a reflective epistemic renegade pretty often. Then, after writing the essay up to the beginning of the presentation of the Self-Application Objection, I'm strongly attracted to (3). At that point I'm thinking that I should change my ways: from here on out I won't be a reflective epistemic renegade (unless I am sure I'm in one of the exception classes) and I will arrange my doxastic life so that I avoid the blameworthiness alleged by the Unfavorable Thesis as well as thesis (3). But now that I have had these puzzling thoughts about (3), brought about by the Self-Application Objection, am I going to change my ways or not?

My answer is that I am going to change my ways. I'm going to act in accord with (3). As already mentioned, I don't believe (3) is true. But I do think it is closer to the truth than other principles (such as: it's virtually always okay to be a reflective epistemic renegade). I don't mean to suggest that it has a high degree of truth but less than 1 (where degree 1 is the full truth). It might be perfectly false, whatever that means. What I base my decision on, and have confidence in, is the idea that (3) is in the vicinity of an important truth. I think (3) is a good rule of thumb, where all that means is that it's in the vicinity of a truth (endorsing a rule of thumb doesn't mean endorsing its truth).

Now of course I could be dead wrong about that: (3) isn't in the vicinity of an important truth. But just because I'm wrong about it, doesn't mean I'm blameworthy in the sense discussed in this essay.

Tenth and final argument. You might think that what distinguishes Lewis and Williamson from yourself has nothing to do with their increased chance at philosophical truth or philosophical justification. You 
may believe that their superiority results in their having comparatively stronger philosophical merits such as:

- $\quad$ Being more prolific

- $\quad$ Being better at coming up with new views and arguments that aren't obviously wrong or unsound and are worth thinking about

- $\quad$ Being better at generating new concepts that increase insight into old philosophical problems

- $\quad$ Noticing more, and more deeply, problems and connections that are important yet were unknown beforehand

- $\quad$ More frequently supporting various interesting and new philosophical ideas

That's just a sample of relevant characteristics, but it's enough to make the initial point, which is that you might implicitly think that although Lewis is your philosophical superior in many ways-so you are not arrogant in that respect-he is no better than you (or not significantly better than you) when it comes to evaluating the truth-value of philosophical ideas-at least when we spell out 'better evaluator' with 'more reliably correct evaluator'. And then you might implicitly think that you are epistemically blameless in disagreeing with him, as you are not aware of anyone who disagrees with you and has a better chance at being right.

There are two relevant issues here. First, there is the question of whether such a parity-of-reliability belief on the part of the renegade is reasonable or true: am I right in having this view of Lewis compared to myself? Second, there is the question of whether the parity-of-reliability belief's truth or reasonableness helps the renegade escape blame.

Regarding the first issue, it is improbable that the parity-of-reliability belief could be true or even reasonable. How likely is it that you reasonably believe that your recognized epistemic superior-who you'll remember is someone you know (a) to be generally more informed than you are on the topics involving $\mathrm{P}$, (b) to have more raw intelligence, (c) to have thought and investigated whether $\mathrm{P}$ is true longer and in more depth than you have, (d) to have thought about and investigated the topics surrounding $P$ longer and in more depth than you have, (e) to be just as or even more intellectually careful than you are, and (f) to have understood and fairly and thoroughly evaluated virtually all the evidence you have seen regarding P (and usually much additional evidence) - is no more likely to get P's truth-value right than you are? This scenario seems highly unlikely (think of non-philosophical 
analogues). ${ }^{29}$ We can retain the idea that if you and the superior had been presented with the exact same pot of evidence and other relevant considerations she would be no more likely than you to get P's truth-value right. But since she is your superior, such a situation doesn't apply.

Even if such a belief could be reasonable, surely you are in no position to think that you have a significantly better chance than the epistemic superior does to get P right. Maybe all her epistemic advantages fail to increase her chances at finding the truth about $P$; this would be an odd and very depressing fact about the activity of philosophizing. But it's hard to see how in the typical case you could justifiably think she is considerably less likely than you to get P right. And if that's so, then the fact that she disagrees with you is still awfully worrisome. All I'm saying here is that the mere fact that you think, even justifiably, that the superior is not more reliable than you isn't sufficient to get you off the hook. One might think that because our renegade justifiably thinks that her epistemic superior is not more relevantly reliable means that we have returned to the epistemic peer problem, briefly discussed in the section 1. However, the renegade and her superior are still not peers, in any of the senses of 'peer' discussed in the literature. But perhaps we have now hit upon the best non-factive notion of recognized epistemic peer: person $A$ justifiably believes that person $B$ is equally likely to get $P$ 's truthvalue right (before $A$ finds out what $B$ actually thinks about $P$ ).

\section{A Surprising Application}

Presumably, if one is blameworthy in continuing to believe $P$, in the sense of blameworthiness we have been discussing, then one doesn't know $P$, even if $P$ is true. If that's right (I won't attempt a defense here), and if my Unfavorable Thesis is true too, and if it's also true that significant expert philosophical endorsement of a purely philosophical thesis typically supplies good testimonial evidence for that thesis (that last claim might strike one as controversial), then we have an intriguing result: kinds of radical skepticism quite different from traditional versions.

Consider possible cases in which (a) the Epistemic Superior situation has come up with respect to my belief in $\mathrm{P}$, (b) I'm not in one of the exception classes, and (c) P is something commonsensical such 'I have a laptop', 'M ary believes that Jon is a moron', 'Torture for political gain is morally wrong', ' $2+2=$ 4', 'Tom knows that our sun is an ordinary star' or any other claim obviously inconsistent with compositional nihilism (almost no composite objects, or at least no composite artifacts; Rosen and Dorr 2002), moral error theory (no positive, first-order, substantive moral truths), eliminative materialism (no beliefs), mathematical error theory (no positive, first-order, substantive mathematical truths), semantic

\footnotetext{
${ }^{29}$ However, what if you are a "commonsense" philosopher in that the only beliefs you stick with have the full backing of today's best science and the commonsense opinion of virtually every culture throughout history? You believe in trees and that $2+2=4$, but not much else. Perhaps you are significantly more reliable than philosophers who don't have such scruples, but not many philosophers are so doxastically frugal.
} 
nihilism (no claims made with vague terms are true; Sider and Braun 2007), or traditional skepticism (virtually no knowledge). So, we're considering claims at odds with anti-commonsensical theories whose adherents are members of philosophical communities in which there are significant numbers and percentages of genuine philosophical experts who truly believe those anti-commonsensical theories. (I am not saying that our present, 2009, philosophical communities meet any of these conditions (this is a sociological matter), but of course they might in the actual future and easily do so in close possible worlds.) Then not only am I blameworthy for continuing with my belief in $\mathrm{P}$, but my belief fails to amount to knowledge. Thus, I don't know that I have a laptop, that $2+2=4$, that M ary believes that Jon is a moron, that I believe that J on is a moron, that I'm in pain, or just about anything else. Clearly, this new skepticism is in some respects more radical than the traditional ones, as it denies more knowledge (you can't even know that dogs are dogs or that $2+2=4$, provided semantic nihilism and mathematical error theory are expertly endorsed in the right way). However, the new skepticism is purely contingent as it depends on the nature of the philosophical circles one is a member of (and thus might not actually apply to any of us right now). Furthermore, if the relevant experts change their minds appropriately (finding serious problems with the anti-commonsensical theories), then the way is clear for my belief to amount to knowledge. Virtually all of your knowledge can be sabotaged due to contingent socio-epistemic facts. And even if this is wrong, so your beliefs continue to meet whatever conditions are sufficient for knowledge (perhaps knowledge isn't all it's been cracked up to be), the knowledge in question will be blameworthy and surely not as epistemically good as knowledge untainted by recognized superior disagreement..$^{30,31}$

\section{References}

Christensen, David. 2007. “Epistemology of Disagreement: the Good News." Philosophical Review 116: 187-217.

Christensen, David. 2009. “Disagreement as Evidence: The Epistemology of Controversy.” Philosophy Compass 4: 756-67.

Elga, Adam. 2007. "Reflection and Disagreement." Noûs 41: 478-502.

${ }^{30}$ I discuss this argument further in my unpublished work.

${ }^{31}$ Drafts of this essay were previously circulated with the title 'Who am I to Disagree with David Lewis?'

Thanks to Allan Hazlett and Margaret Frances for detailed feedback. Special thanks to Margaret for coining the term 'epistemic renegade'. Thanks to the excellent and generous referees as well. Thanks to Adam Elga and Sandy Goldberg for email comments. Thanks to the audiences at the 2007 Bled Conference on Epistemology, in Slovenia, and the 2007 Russell III Conference, in California. Finally, thanks to the participants of the 2006 web discussion of the entry "Disagreement with Philosophical Superiors" on the Certain Doubts website run by Jonathan Kvanvig. 
Feldman, Richard. 2007. "Reasonable Religious Disagreements." In Philosophers Without Gods:

Meditations on Atheism and the Secular Life, edited by Louise Antony. Oxford: Oxford University Press.

Feldman, Richard. 2006. “Epistemological Puzzles About Disagreement." In Epistemology Futures, edited by Stephen Hetherington. Oxford: Oxford University Press.

Frances, Bryan. Forthcoming. "Discovering Disagreeing Peers and Superiors." International J ournal of Philosophical Studies.

Frances, Bryan. 2010. “Disagreement." In Routledge Companion to Epistemology, edited by Duncan Pritchard and Sven Bernecker. Routledge.

Frances, Bryan. 2008a. "Live Skeptical Hypotheses." In Oxford Handbook of Skepticism, edited by John Greco. Oxford: Oxford University Press.

Frances, Bryan. 2008b. "Spirituality, Expertise, and Philosophers." In Oxford Studies in Philosophy of Religion, vol. 1, edited by Jon Kvanvig. Oxford: Oxford University Press.

Frances, Bryan. 2005a. Scepticism Comes Alive. Oxford: Oxford University Press.

Frances, Bryan. 2005b. "When a Skeptical Hypothesis is Live." Noûs 39: 559-95.

Kelly, Thomas. 2010. "Peer Disagreement and Higher Order Evidence." In Disagreement, edited by Richard Feldman and Ted Warfield. Oxford: Oxford University Press.

Kelly, Thomas. 2006. "The Epistemic Significance of Disagreement." In Oxford Studies in Epistemology, 1, edited by John Hawthorne and Tamar Gendler Szabo. Oxford: Oxford University Press.

Lackey, Jennifer. Forthcoming A. "A Justificationist View of Disagreement's Epistemic Significance," in Adrian Haddock, Alan Millar, and Duncan Pritchard (eds.), Social Epistemology, Oxford: Oxford University Press.

Lackey, Jennifer. Forthcoming B. "What Should We Do When We Disagree?" in Tamar Szabó Gendler and John Hawthorne (eds.), Oxford Studies in Epistemology, v. 2, Oxford: Oxford University Press.

Rosen, Gideon and Dorr, Cian. 2002. "Composition as Fiction." In The Blackwell Guide to M etaphysics, edited by Richard M. Gale. Oxford: Blackwell.

Sider, Theodore and Braun, David. 2007. "Vague, So Untrue." Noûs 41: 133-156.

van Inwagen, Peter. 1996. "Is It Wrong, Everywhere, Always, and for Anyone to Believe Anything on Insufficient Evidence?" In Faith, Freedom, and Rationality, edited by Jeff Jordan and Daniel Howard-Snyder. Lanham, M D: Rowman and Littlefield.

White, Roger. 2005. “Epistemic Permissiveness." Philosophical Perspectives 19: 445-59. 